\title{
Conflict, Defense Spending, and the Number of Nations
}

\section{Citation}

Alesina, Alberto, and Enrico Spolaore. 2006. Conflict, defense spending, and the number of nations. European Economic Review 50(1): 91-120.

\section{Published Version}

doi:10.1016/j.euroecorev.2004.06.003

\section{Permanent link}

http://nrs.harvard.edu/urn-3:HUL.InstRepos:4553016

\section{Terms of Use}

This article was downloaded from Harvard University's DASH repository, and is made available under the terms and conditions applicable to Other Posted Material, as set forth at http:// nrs.harvard.edu/urn-3:HUL.InstRepos:dash.current.terms-of-use\#LAA

\section{Share Your Story}

The Harvard community has made this article openly available.

Please share how this access benefits you. Submit a story.

Accessibility 
INTERNATIONAL CONFLICT, DEFENSE SPENDING AND THE SIZE

OF COUNTRIES

\author{
Alberto Alesina \\ Enrico Spolaore
}

NBER Working Paper 5694

\title{
NATIONAL BUREAU OF ECONOMIC RESEARCH 1050 Massachusetts Avenue Cambridge, MA 02138 \\ August 1996
}

We are greatly indebted to Gian Maria Milesi Ferretti, for useful conversations and for helping us with one of the proofs. We also thank Jordan Rappaport for excellent research assistance. This research is supported by and NSF grant. This paper is part of NBER's research program in Monetary Economics. Any opinions expressed are those of the authors and not those of the National Bureau of Economic Research.

(C) 1996 by Alberto Alesina and Enrico Spolaore. All rights reserved. Short sections of text, not to exceed two paragraphs, may be quoted without explicit permission provided that full credit, including $\mathbb{C}$ notice, is given to the source. 


\title{
INTERNATIONAL CONFLICT, DEFENSE SPENDING AND THE SIZE \\ OF COUNTRIES
}

\begin{abstract}
This paper provides a formal model of endogenous country formation and of choice of defense spending in a world with international conflict. The model is consistent with three observations. First, secessions and, more generally, break-up of countries should follow a reduction in the likelihood of international conflict. Second, the number of regional conflicts between smaller countries may increase as a result of the break-up of larger countries. Third, the size of the peace divided -- i.e., the reduction in the defense spending in a more peaceful world -- is limited by the process of country break-up.
\end{abstract}
Alberto Alesina
Department of Economics
Enrico Spolaore
Littauer 200
Department of Economics
Harvard University
Ohio State University
Cambridge, MA 02138
410 Arps Hall
and NBER
1945 North High Street
email: aalesina@imf.org
Columbus, $\mathrm{OH} 43210-1172$ 


\section{Introduction}

The end of the cold war has been accompanied by a sweeping process of democratization, creation of new countries and political separatism. However, even though the probability of a confrontation between the two blocs of the cold war era is greatly diminished, the number of localized, regional conflicts has not decreased; several observers have in fact argued that one should expect more regional conflicts after the end of the cold war.

This paper provides a model which is consistent with both these observations. First, it implies an increase in the number of countries as a consequence of a reduction in the probability of international conflict. Second, it argues that a reduction in the probability of conflict among a few large countries, by increasing the number of smaller countries, may increase the number of conflicts between the more numerous, smaller independent political units. A related observation concerns the extent of the "peace dividend," i.e., the reduction in military spending following the end of the cold war. Our model suggests that the worldwide "peace dividend" may be smaller than one might expect. The reason is that the per capita costs of defense may increase in smaller countries that have to deal with more numerous potential regional conflicts.

This paper joins two strands of the analytical literature. One is the economic literature on the size of countries, as in the work by Friedman (1977), Casella and Feinstein (1990) and Wei (1992). ${ }^{1}$ Specifically, we build upon Alesina and Spolaore (1995), where 
we model the equilibrium number of countries as emerging from a trade off: the benefits of economies of scale in the production of non-rival public goods against the costs of heterogeneity in the population. In the present paper an additional benefit of size arises from the consideration of potential international conflicts and the cost of defense. The second line of research is the literature on conflict resolution and arms races recently surveyed by Sandler and Hartley (1995). Classic references are Schelling (1960), Boulding (1962), Olson and Zeckhauser (1966) and Tullock (1974). In particular, in our formalization of the technology of conflict resolution, we follow Hirshleifer $(1989,1995) .^{2}$

This paper is organized as follows. Section 2 describes the model. Section 3 illustrates the 'domestic' equilibrium on the choice of defense and non defense spending. Section 4 characterizes a symmetric equilibrium in which the number and size of countries is endogenously determined. Section 5 discusses issues of stability, and specifically, unilateral secessions. The last section concludes.

\section{The Model}

The world is modeled as a segment of length normalized to $1 .^{3}$ The world population has mass 1 and is uniformly distributed on the segment $[0,1]$. A country is defined by two borders and a non-rival public good, which we label the 'government'. Each individual can

${ }^{2}$ See also Tullock (1980) and Garfinkel (1994).

${ }^{3}$ We could model the world as a circle, but this modeling choice, even though it would produce qualitatively similar results would introduce unnecessary complications. 
only use one public good, i.e., 1 government, and individual utility is decreasing in the distance from the government of the country to which the individual belongs. The distance of individual $i$ from his government is denoted $l_{i}$. We assume that this distance captures both a geographical and a preference dimension. That is, being "far" from the government implies being distant both in geographical location and preferences; in other words, if two individuals live far from each other, they are also distant in preferences. Hence, the location of a government captures both a position on an ideological dimension and on a geographical line. As discussed in more detail in Alesina and Spolaore (1995), this assumption ensures that countries are geographically connected. An alternative assumption would be to retain only the preference interpretation of distance and then impose costs on non geographically connected countries. For the purpose of this paper the "preference" interpretation of distance is not necessary, although it makes the model richer.

Individual utility is given by:

$$
U_{i}=z_{i}-t_{i}-g l_{i}
$$

where $z_{i}$ is the total income available to individual $i, t_{i}$ are his taxes, $l_{i}$ is the distance of individual $i$ from his government, and $g$ is a positive parameter. Thus, individual utility is linear in private consumption $\left(z_{i}-t_{i}\right)$ and linear in the distance from the public good. The utility deriving from the public good is highest for $l_{i}=0$. 
The cost of a government is $K$, irrespectively of the size of the country. This specification captures in the simplest possible way the benefit of "size" of a country. ${ }^{4}$ In fact, with a fixed cost of government the average per capita cost of financing is decreasing with the size of the country.

In reality, the benefits of country size derive from several fixed costs, including creating and maintaining a monetary system, a bureaucracy, a tax collection system. Also, in a world of less than perfect free trade, the size of markets is affected by the size of political jurisdictions. In the extreme case of complete autarky the two coincide: the market size is the size of the country. Thus, in any model with increasing returns in the size of the market economy, and some barriers to international trade, income is increasing in the size of the country. ${ }^{5}$ Also, even though this argument is not explicitly accounted for in the model, a large country can provide insurance to its regions, needed because of regional idiosyncratic shocks. ${ }^{6}$ Thus, in equilibrium the size of countries emerges from a trade-off. Large countries can take advantage of the benefits of size, but are less homogeneous since a larger population has more diverse preferences. As the size of a country increases, the cost per capita of government decreases, but the average distance from the government, i.e., heterogeneity increases.

${ }^{4}$ A more general specification would be to impose $K=\alpha+\beta s$ where $s$ is the size of the country. As long as $\alpha>0$ our results would be qualitatively unchanged.

${ }^{5}$ See Alesina and Spolaore (1995) and Spolaore (1995b) for more discussion on this point

${ }^{6}$ See Sachs and Sala-i-Martin (1992) for an empirical discussion of regional insurance schemes in the US. 
We now consider the role of international conflict and defense spending. Individual resources $z_{i}$ are divided into two components:

$$
z_{i}=y+e_{i}
$$

$y$ is individual income (equal for everybody), which is "safe" from the consequences of conflict; $e_{i}$ is the expected amount of resources available to individual $i$ after a (possible) international conflict is resolved.

Conflict is modeled as follows. Individuals are randomly matched pairwise. When a pair $(i, j)$ meets, the two individuals generate a pool of resources equal to $2 e$ which has to be divided. There are two possible states: conflict $(c)$ and no conflict $(n c)$. In a state of $n c$ resources are distributed (peacefully) and equally:

$$
e_{i}=e_{j}=e
$$

We assume that:

A1: If two individuals who belong to the same country meet, they are always in a state of no conflict.

If two individuals, $i$ and $j$, who do not belong to the same country meet, they can either be in conflict or in no conflict, in which case (3) applies. Conflict occurs with probability $p(i, j)$. The following assumption generates a role for defense spending: 
A2: If conflict occurs, the share of individual $i$ depends on the defense spending of his country, relative to defense spending of the country of individual $j$ :

$$
e_{i}=\frac{\psi\left(d_{i}\right)}{\psi\left(d_{i}\right)+\psi\left(d_{j}\right)} 2 e
$$

where $d_{i}\left(d_{j}\right)$ is the defense spending in the country of individual $i(j)$ and $\psi^{\prime}>0$.

The rationale behind these assumptions should be clear. A1 rules out domestic conflict. In fact we could assume an additional cost for a country for internal "law and order" and conflict resolution (courts, legal system etc.). If this cost were increasing in the size of the country, it would provide an additional argument for the costs of size, in addition to the "average distance" argument emphasized above. If these costs were linear, our results would be completely unaffected. If these costs were decreasing in the size of countries (i.e., economies of scale in law and order) they would provide an additional benefit for size.

The second assumption borrows from the literature on conflict resolution, and in particular from Tullock (1980), Hirshleifer $(1989,1995)$ and Garfinkel $(1994)$. The idea is that the benefits for the individuals of a certain country in case of international conflict are increasing in the military strength of the country relative to the opponent. We are assuming that spending on defense translates into military strength. Thus we are abstracting from different 'productivities' of defense spending in different countries. "Conflict" in our model should be interpreted quite generally as a war (cold or hot), military "muscle flexing" or 
simply the weight in intemational trade bargaining tables arising from a country's strength.

Thus, the potential conflict between two individuals may stem from a trade relationship, or from conflicting interests on natural resources and/or other economic and noneconomic issues.

For tractability we make two simplifying assumptions:

$+3$

At

$$
\begin{gathered}
\psi\left(d_{i}\right)=d_{i} \\
p(i, j)=p \quad \text { for every } i, j .
\end{gathered}
$$

The second one represents a drastic simplification since it implies that all individuals have the same probability of being matched. Hence, it implies that the probability of a match is independent of the distance between the pair, and independent of the country of origin of the two individuals.' Extensions on this point would substantially complicate notations and computations, but should not change the qualitative nature of our results.

Suppose that the world is divided in $N$ countries, indexed by $h$, of size $s_{h}, h=1, \ldots N$. Then, the value of $e_{1}$ is given by:

$$
e_{1}=\left[1-\left(1-s_{h}\right) p\right] e+\left(1-s_{h}\right) p \sum_{h^{\prime} \cdot h} \frac{s_{h^{\prime}}}{1-s_{h}} \frac{d_{h}}{d_{h h^{\prime}}+d_{h^{\prime}}} 2 e
$$

for an individual $i$ belonging to country $h$.

"This aysumption is analogouy to the assumption of "panmictic matching" which is standard in the lormal biological literature: "... Panmixia means thut each reproductively mature male is equally likcly to mole with each repraductively mature iemule, regardless of their locition within the range of the deme. Althuugh not likely to be allained in absolute form in nature ... panmixia is an important simplifying assumption made in much of elementary quantitative theory" (Wilson, 1980, p.8). 
The first term in (7) represents the payoff of no conflict $(e)$ multiplied by the likelihood of either not being matched with a foreigner, or being matched peacefully with a foreigner. The second terms represent the probability of being matched to a foreigner with conflict [(1- $\left.\left.s_{h}\right) p\right]$ multiplied by the outcome of conflict, which depends on relative defense spending $\left(\frac{d_{n}}{d_{n}+d_{h^{\prime}}}\right)$ multiplied by the probability of meeting citizens of the various countries $\left(\frac{s_{h^{\prime}}}{1-s_{h}}\right)$.

Finally, for country $h$, extending from borders $\underline{b}$ to $\bar{b}$, the budget constraints is given by:

$$
\int_{\underline{b}}^{\bar{b}} t_{i} d i=K+d_{h}
$$

Equation (8) indicates that the total tax revenues have to equal the total of non defense spending $(K)$ and defense spending $\left(d_{h}\right)$.

\section{Voting on Government and Defense}

Individuals vote by majority rule on the location (type) of government and on the size of defense. We make the following two assumptions:

A5 Voting on the location of government and the size of defense occur after the country borders have been established.

This is a natural assumption since it implies that policy decisions on the type of government and the amount of defense spending can be taken only after a country is created. A6 In each country, taxes are the same for everyone. 
Two observations emerge immediately from the structure of the model:

i) For given borders, every citizen has the same preferences on the optimal amount of defense; and

ii) The government is located in the middle of the country.

The first observation derives from the fact, embodied in (7), that every individual has the same probability of meeting a foreigner and individual payoffs all depend identically on the country's aggregate level of defense. This result would not hold if, for instance, individuals close to the borders had a higher change of engaging in conflicts with foreigners. In the latter case, border individuals would prefer a higher spending on defense.

The second result derives from a straightforward application of the median voter theorem over the choice of location of the government, noting that this choice, by assumption, does not influence individuals' taxes, nor their desired amount of defense. Assumption A6 implies that taxes cannot be a function of the (unique) parameter which varies across individuals: the distance from the government. This assumption can be justified in two ways. First, to the extent that individual location captures a preference dimension, unobservability of preferences would imply that taxes linked to preferences are generally unfeasible. $^{8}$ Second, Alesina and Spolaore (1995) derive this assumption as a result of a realistic voting process on the distribution of the tax burden. With the same tax for everyone, individuals close to the government are better off than those far from it. If taxes

\footnotetext{
${ }^{8}$ We do not explore here a connection with the literature on revelation mechanisms.
} 
were decided by majority vote, those individuals who are far from the government would favor tax compensation schemes in their favor. Such schemes might also enforce larger countries, by keeping border individuals "in", with tax advantages. Alesina and Spolaore (1995) consider linear taxation schemes, where the tax rate is a linear function of the distance from the government. They show that, under some weak assumptions, if voting on taxes occurs after country borders are decided (exactly as assumption $\mathbf{A 5}$ requires), then the voting equilibrium implies the same tax for everyone and the government located in the middle. The intuition is that for given borders, fifty percent of the voters (those with a distance from the government above average) would like to maximize compensations. The other half would want to minimize them. The tie is broken if one assumes even infinitesimal implementation costs of these transfer schemes. In summary, under realistic assumptions on the order of voting, a majority would favor equal taxes. Thus, A6 could be derived as a result, rather than imposed as an assumption. Since our focus here is not on compensation schemes, we simply impose $\mathbf{A} 6$ from the start.

With taxes equal for every citizen the budget constraint for country $h$ of size $s_{h}$ implies:

$$
t_{h}=\frac{K+d_{h}}{s_{h}}
$$

The first order condition which determines the desired amount of defense by each individual of country $h$ is obtained using (1), (7), and (9) as follows: 


$$
-\frac{1}{s_{h}}+p \sum_{h^{\prime} \neq h} s_{j} \frac{d_{h}^{\prime}}{\left(d_{h}+d_{h}^{\prime}\right)^{2}} 2 e=0
$$

Equation (10) shows that the marginal costs of an extra unit of defense spending (equal to

$\frac{1}{s_{h}}$, from (9)) have to equal the marginal benefits, in terms of a higher 'prize' in case of conflicts, which is the second term in (10) obtained from (7).

\section{The Equilibrium Number of Countries}

We now characterize an equilibrium number of countries. In the next section we discuss its stability, including the possibility of unilateral secessions. The first requirement which we impose on an equilibrium configuration of borders is the following:

Requirement 1: No individual (or group of individuals) can be forced to belong to an existing country if he prefers to belong to a different one.

This feature of equilibrium is a benchmark, in which countries cannot impose restrictions on individuals who want to join or exit. Remember that individuals are not physically mobile. Thus "joining a country" means moving the border of that country. This requirement implies a condition of indifference at the border: the individual at the border must be indifferent on the choice of which country to belong to. The following result is immediate:

\section{Proposition 1.}

Countries of equal size, with the government located in the middle and with the same amount of defense spending, satisfy Requirement 1. 
The proof is immediate, remembering that everyone pays the same tax. Proposition 1 does not imply that the only type of equilibria which satisfies Requirement 1 has countries of equal size. We return on this point in section 5 in the context of our discussion of stability. Note, however, that given our assumption of uniform distribution of individuals, equilibria with equally-sized countries are the natural candidates. In turn, if all the countries have equal size, the natural candidates for an equilibrium is the symmetric one, with each country spending the same amount on defense. Using (10), the symmetric equilibrium with $N$ countries of equal size $s$ (so that $N=\frac{1}{s}$ ) implies that each country spends $d^{*}$ in defense:

$$
d^{*}=\frac{s(1-s) p e}{2}
$$

Several observations are in order. First, the equilibrium amount of defense is increasing in the probability of conflict. Not surprisingly, it is also increasing in the amount of the payoff from conflict $e$. Second, defense spending is zero when there is only one country in the world, since, by definition, there is no conflict. Third, defense pro capita, which is:

$$
\frac{d^{*}}{s}=\frac{(1-s) p e}{2}
$$

is decreasing with country size. Larger countries have, in equilibrium, a lower per capita defense bill. Fourth, since defense is, from the point of view of global efficiency, pure 
waste, individual utility would be maximized if $p=0$ and $d^{*}=0$. In fact, if $p>0$ and $d_{h}=d^{*}$ for every country using (7) one can verify that $e_{i}=e$ for every $i$, exactly as in the case of $p=0$. When $p>0$, however, the "price" of the payoff $e$ is the per capita cost of defense given in (12). Obviously, we have a suboptimal Nash equilibrium on defense spending.

Empirically, the relationship between country size and defense per capita is influenced by two critical factors which our model does not capture: the existence of military alliances, and the fact that smaller members of an alliance can free ride on the defense capabilities of the larger member(s). ${ }^{9}$ Both considerations are very important, and we do not mean to downplay them. However, we see our model as a stepping stone upon which to build these additional realistic features.

We now consider border redrawing by majority rule. We allow the existing countries to eliminate a country or create a new country if the border change is approved by majority rule in each of the countries whose borders are affected by the change. We restrict voting only on proposals of border redrawing which satisfy Requirement 1.

Requirement 2. Given a configuration of countries that satisfies Requirement 1 , in at least one country a majority should oppose any proposal to redraw borders so that a new country is created or eliminated. Only proposals that satisfy Requirement 1 are admissible.

${ }^{9}$ For a survey of the literature on this point, see Sandler and Hartley (1995). 
In other words, this requirement implies that in an equilibrium at least one country would veto any border rearrangement. Thus, we are trying to capture situations like referenda on the choice of joining politico-economic unions (like the European Union), or post-war international conferences to settle border disputes, or, more generally, border rearrangements which are the result of some form of international agreement, rather than the result of unilateral secessions, which we study in the next section.

\section{Proposition 2.}

The number of equally-sized countries which satisfies Requirement 2 is given by the integer that is closest to:

$$
\sqrt{\frac{g-p e}{2 K}}
$$

\section{Proof: See Appendix.}

For the sake of simplicity in exposition, from now we will abstract from the integer condition and assume that $\tilde{N} \equiv \sqrt{\frac{g-p e}{2 K}}$ is the equilibrium number of countries.

Corollary: The equilibrium number of countries is decreasing with the probability of conflict. The size of countries is increasing with the probability of conflict.

This is one of the critical results of the paper: it implies that a sharp decrease in the probability of conflict would result in the break-up of countries. Two forces underlie this 
inverse relationship between $p$ and $\tilde{N}$. First, if $p$ increases, an individual would like to belong to a larger country in order to reduce the probability of "being matched" with foreigners. Second, since defense spending increases in $p$ and defense per capita is decreasing in larger countries, the benefits of size increase. If we view the end of the cold war as a large drop in $p$, the model predicts that the creation of new countries should go hand in hand with the end of the cold war.

One could expect that a large fall in the probability of conflict $p$ (The "end of the cold war," should bring about a more peaceful world and a "peace dividend", namely a reduction in the per capita cost of defense. However, the emergence of several local conflicts cast doubt on the first implication, and the "peace dividend" has been slow in materializing. Our model is consistent with both these rather sad observations.

Let's begin with the amount of world conflict. Define the mass of observable conflict $M$. We have that:

$$
M(p)=p(1-\tilde{s}(p))
$$

where $\tilde{s}(p)$ is the equilibrium size of countries Thus, from Proposition 2:

$$
\tilde{s}(p)=\sqrt{\frac{2 K}{g-p e}}
$$




\section{Proposition 3}

The mass of international conflicts is increasing in $p$ if and only if:

$$
\tilde{s}(p)<\frac{g-p e}{g-p e / 2}
$$

Proof: From (14):

$$
\frac{d M(p)}{d p}=1-\tilde{s}(p)-p \frac{d \tilde{s}(p)}{d p}
$$

substitute $\tilde{s}(p)$ and $\frac{d \tilde{s}(p)}{d p}$ using (15) to obtain (16). Q.E.D.

The intuition of Proposition 3 is that a reduction in $p$ has two effects. For a given size of countries, it reduces the mass of international conflict. This direct effect is larger the smaller is $s$, namely the larger the "mass" of international "matches", relative to domestic "matches". The second, and indirect effect, is that a reduction in $p$ reduces the size of countries, thus it increases the mass of international interactions that can, potentially, lead to conflict. As equation (16) shows, for $\tilde{s}$ small the direct effect dominates, for $\tilde{s}$ large it does not. Therefore, starting from a world with a few large countries a reduction in $p$ which leads to the formation of many new countries may actually increase the mass of observed conflicts. 
A similar intuition underlies the effect of a reduction of $p$ on defense spending per capita. From (12) it follows that:

$$
\frac{\partial\left(d^{*} / s\right)}{\partial p}=\frac{(1-s) e}{2}-\frac{p e}{2} \frac{d s}{d p}
$$

The first term is the direct positive effect of a change in $p$ on defense per capita: a lower $p$ leads to lower defense. The second term, with the opposite sign, is the indirect effect due to the consequences of a change in $p$ on the size of countries. Equation (18) leads to the following:

\section{Proposition 4.}

A reduction in $p$ determines a reduction of defense per capita if and only if:

$$
\tilde{s}(p)<\frac{g-p e}{g-p e / 2}
$$

Thus, a reduction of $p$ may actually lead to an increase in defense spending per capita because countries become smaller. More generally, even when (19) holds, so that lower $p$ means lower defense, the model emphasizes a channel (through the size of countries) which reduces the effect of $p$ on $\frac{d^{*}}{s}$. 


\section{Stability}

In this section we consider the issue of stability of the equilibrium both to small perturbations and to unilateral secessions. We begin with small perturbations in which one border is moved slightly, so that a small mass $\varepsilon$ of population changes country.

Requirement 3 ( $\varepsilon-$ Stability ): A configuration of countries is stable if after a small $\varepsilon$ perturbation of the border between two countries, the original equilibrium is re-established.

Consider a configuration of $N$ countries of equal size. We know that this configuration of borders satisfies Requirement 1. But is it stable? Suppose, without loss of generality, that starting from the equilibrium with $N$ countries of size $s=\frac{1}{N}$, country 1 is reduced to size $s_{1}^{\prime}=s-\varepsilon$ and country 2 to size $s_{2}^{\prime}=s+\varepsilon$. Would the original equilibrium be restored? Namely, would the mass of individual $\varepsilon$ want to return to country 1 ? When the size of two countries changes the following adjustments occur:

i) the type (location) of government in country 1 and 2:

ii) the defense spending of countries 1 and 2; and

iii) the defense spending of all the other $(N-2)$ countries. $^{10}$

Intuitively, the third adjustment is "second order," particularly for $N$ large. In fact, looking at the first order condition (equation (10)) one immediately verifies that the $(N-2)$ countries not affected by the border perturbation change their choice only marginally because

\footnotetext{
${ }^{10}$ Note that the location-type of government in these $(N-2)$ countries does not change, because their borders do not change.
} 
the size of the other two countries have been reshuffled. We can obtain analytical results under the simplifying assumption that the third type of adjustment is zero, namely the $(N-2)$ countries not affected by the border change maintain their defense spending fixed. In this case we can show the following:

\section{Proposition 5.}

Consider a configuration of $N$ equally sized countries. If all the $(N-2)$ countries not affected by the border change maintain their level of defense fixed, the smallest size of countries which is stable, $\hat{s}$, is a function of $p, \hat{s}(p)$ such that:

$$
\begin{aligned}
& \hat{s}(0) \leq \hat{s}(p) \quad p>0 \\
& \frac{\partial \hat{s}(p)}{\partial p} \geq 0
\end{aligned}
$$

Proof: See Appendix.

Thus, the minimum stable size is (weakly) increasing $p$. If $p$ is high, small countries are not stable in the sense that if a perturbation makes one country larger, the citizens of the neighboring smaller countries would want to join the bigger country, because defense is too expensive in the smaller country. Thus, the implication of Proposition 5 is that, even leaving aside Requirement 2, the minimum stable size of countries (weakly) 
increases in $p$ : with a higher probability of conflict, the minimum stable size of countries is larger. ${ }^{11}$

We can now extend our analysis of Requirement 2 to the case where we explicitly take into account the issue of $\varepsilon$ - stability. Namely we modify Requirement 2 as follows:

Requirement $2^{\prime}$ : Given a configuration of countries that satisfies Requirement 3 , in at least one country a majority should oppose any proposal to redraw borders so that a new country is created or eliminated. Only proposals which satisfy Requirement 1 and 3 are admissible.

Numerical simulations described in Appendix show the following:

\section{Results.}

a) The maximum number of equally-sized countries that satisfies Requirement 3 is decreasing in $\mathrm{p}$;

b) The number of equally-sized countries $N$ that satisfies Requirement $2^{\prime}$ is the integer closest to $\sqrt{\frac{g-p e}{2 K}}$ (Or, for small values of $p e$, the largest integer smaller than $\sqrt{\frac{g-p e}{2 K}}$ ).

For large values of $\sqrt{\frac{g-p e}{2 K}}$, we can ignore the integer condition and approximate the number of countries that satisfies Requirement $2^{\prime}$ by $\tilde{N} \equiv \sqrt{\frac{g-p e}{2 K}}$. This number, therefore, not only approximates the equilibrium number of countries that satisfies 
Requirements 1 and 2, but also the stable number of countries that satisfies Requirements 3 and $2^{\prime}$.

We now turn to the issue of stability to unilateral secessions. A unilateral secession occurs when a (connected) set of individuals belonging to an existing country unilaterally forms a new country.

Definition: A country of size $s$ is secession free, if no group of citizens would want to unilaterally break away and form a new country.

First of all, note that if a secession occurs, three adjustments have to occur:

i) the location of government and defense spending of the new country;

ii) the location of government and the defense spending of the country which has been split, and

iii) the defense spending of all the other countries not affected by the secession.

While for the case of the $\varepsilon$ - stability the third adjustment was "second order," this is not the case for (potentially large) unilateral secessions. Thus, we cannot derive results analogous to Proposition 5.

Note that the individuals with the highest incentives to break away are those located far away from the government near the borders of the original country. In fact, for given country size, and given size of a secession, those who gain the most are those who were far from the original government and are much closer to the government of the new country. Clearly, the possibility of secessions impose an upper limit on country size. If a country is too large, a fraction of its citizens at the border would break away because they are so far 
from the government that they are willing to bear the costs of a higher defense bill and total tax per capita, and lower total defense in a conflictual world.

The first question which we ask is whether the configuration of $\tilde{N}$ countries of equal size $\tilde{s}=\frac{1}{\tilde{N}}$ is secession free. Numerical simulations described in the Appendix show the following results:

Result. The size $\tilde{s}$ is secession free.

The simulations imply a search over a grid of values for possible secession sizes. We then check whether or not all the individuals in the proposed break away region are better off after the secession. A country is secession free if we cannot find a size for a possible secession in which all the individuals who are breaking away are better off. Note that this procedure implies (rather realistically) that nobody can be forced to unilaterally break away from an existing country against his will.

A second interesting question is the following. Leaving aside Requirement 2, what is the relationship between $p$ and the minimum size which is secession free? By numerical simulations, described in Appendix we obtain the following:

Result: The maximum size that is secession free is increasing in $p$.

In other words, when the probability of a conflict increases, larger countries that would not have been secession-free for a smaller $p$ become secession free. Conversely, a sharp drop in $p$ would induce certain regions to secede, which would not have seceded with a higher $p$. Therefore, even leaving aside the equilibrium number of countries $\tilde{N}$ obtained 
applying Requirement 2, this result on secessions establishes that one should observe a break-up of countries when, for whatever reason, the probability of conflict decreases.

This observation is quite important because it underlies the generality of the direct relationship between country size and probability of international conflict. In fact, this relationship emerges simply as a result of the secession-free requirement, regardless of any other requirement which (like Requirement 2) identifies a specific equilibrium number of countries.

\section{Conclusions}

This paper provides a model consistent with three observations. First, secessions and, more generally, break-up of countries should go hand in hand with a reduction of international conflict. Second, the number of conflicts among small countries may go up, as a result of the break-up of previous larger political units. Third, the size of the 'peace dividend' is influenced by the process of country break-up which follows the reduction in the likelihood of international conflict.

While these implications of the model appear quite consistent with recent events, we should emphasize several limitations of our approach. First and foremost, we have completely ignored the role of alliances and the related problem of free riding in defense spending by smaller members. To some extent, one can reinterpret the 'country' of our model as a group of allied countries, and view our model of country formation as a model of alliance formation. However, the analogy can be pushed only to a point, because critical 
issues of bargaining (and free riding) amongst allied countries cannot be addressed. Second, our model of conflict is somewhat rudimentary, since we assumed that the probability of conflict amongst citizens of different countries is the same around the world. It could be interesting to consider extensions in which the probability of conflict between groups of individuals may depend on their geographical and/or preference distance, and/or on other political, economic and social characteristics. Third, we almost exclusively focused on symmetric equilibria. Fourth, the equilibrium concepts we have used to determine the endogenous configuration of countries are based on "self determination" and voting mechanisms. Although these concepts may be appropriate to study a completely democratic world, they are far from realistic, especially in situations of international conflict. However, the general principles behind our results are likely to be robust with respect to different specifications of the process of country formation. For instance, Spolaore (1995a) derives similar results for the case of a world in which governments are modeled as rent-maximizing Leviathans. Fifth, our assumption concerning the identity between the geographic and preference dimension excludes the consideration of ethnic minorities. In the context of our model, in fact, an ethnic minority could be viewed as a group of individuals with preferences very different from those of individuals on their right and left geographically. In reality, the existence of ethnic minorities is a critical determinant of both country formation and secessions and of regional conflicts. More generally, focusing on continuous, uniform distinctions of individual characteristics allows us to study some important and robust relationships between conflict, defense and country size with the minimum amount of 
notational and analytical complexity. However, additional insights can probably be obtained by extending and modifying the basic framework in order to allow for asymmetries and discontinuities. These extensions are left for future research.

Despite all these caveats, the contribution of this paper consists in building if not a bridge at least a wire between the literature on country formation and the literature on international conflict and defense spending. 


\section{Appendix}

\section{Proof of Proposition 2.}

Let $l_{i h}\{N\}$ denote the distance of individual $i$, belonging to country $h$, from his country's government when the world is divided in $N$ countries of equal size $s=1 / N$, and let $t_{i h}\{N\}$ denote the taxes paid by $i$. Each individual $i$ in country $h$ will prefer $N$ to $N+1$ countries if and only if:

$$
t_{i h}\{N\}+g l_{i h}\{N\} \leq t_{i h}\{N+1\}+g l_{i h}\{N+1\}
$$

That is:

$$
t_{i h^{\prime}}\{N+1\}-t_{i h}\{N\} \geq g\left[l_{i h}\{N\}-l_{i h^{\prime}}\{N+1\}\right]
$$

Since:

$$
\begin{gathered}
t_{i h}\{N\}=N K+\left(1-\frac{1}{N}\right) \frac{p e}{2} \\
t_{i h}\{N+1\}=(N+1) K+\left(1-\frac{1}{N+1}\right) \frac{p e}{2}
\end{gathered}
$$

we have that, for every individual $i$ in each country $h$ : 


$$
t_{i h^{\prime}}\{N+1\}-t_{i h}\{N\}=K+\frac{p e}{2 N(N+1)}
$$

Denote with $l_{m h}\{N\}-l_{m h^{\prime}}\{N+1\}$ the median distance change in country $h$. It can be shown ${ }^{12}$ that the median distance change is the same in all countries, and equal to:

$$
l_{m}\{N\}-l_{m}\{N+1\}=\frac{1}{2 N(N+1)}
$$

Hence, $N$ is always preferred to $N+1$ in all countries if and only if:

$$
K+\frac{p e}{2 N(N+1)} \geq \frac{g}{2 N(N+1)}
$$

which is satisfied if and only if:

$$
N(N+1) \geq \frac{g-p e}{2 K}
$$

Analogously, each individual $i$ in country $h$ will prefer $N$ to $N-1$ if and only if:

\footnotetext{
${ }^{12} \mathrm{~A}$ proof by construction is provided in Alesina and Spolaore (1995), Appendix, Lemma 1.
} 


$$
t_{i h}\{N\}+g l_{i h^{\prime}}\{N\} \leq t_{i h}\{N-1\}+g\left[l_{i h^{\prime}}\{N-1\}-l_{i h}\{N\}\right]
$$

That is:

$$
t_{i h}\{N\}-t_{i h^{\prime}}\{N-1\} \leq g\left[l_{i h^{\prime}}\{N-1\}-l_{i n}\{N\}\right]
$$

It is immediate to verify that, for every $i$ in each country $h$, we have:

$$
t_{i h}\{N\}-t_{i h^{\prime}}\{N-1\}=K+\frac{p e}{2 N(N-1)}
$$

$N$ will satisfy requirement 2 only if there exists at least one country $h$ in which:

$$
K+\frac{p e}{2 N(N-1)} \leq g\left[l_{m h^{\prime}}\{N-1\}-l_{m h}\{N\}\right]
$$

It can be shown ${ }^{13}$ that, for any $N$, the maximum median distance change $l_{m h^{\prime}}\{N-1\}-l_{m h}\{N\}$ is given by:

\footnotetext{
${ }^{13} \mathrm{~A}$ proof by construction is provided in Alesina and Spolaore (1995). Appendix, Lemma 2.
} 


$$
l_{m h^{\prime}}\{N-1\}-l_{m h}\{N\}=\frac{1}{2 N(N-1)}
$$

Therefore, there exists no country $h$ in which the median voter prefers $N-1$ to $N$ if and only if:

$$
K+\frac{p e}{2 N(N-1)} \leq \frac{g}{2 N(N-1)}
$$

which is satisfied if and only if:

$$
N(N-1) \leq \frac{g-p e}{2 K}
$$

Hence, $N$ satisfies requirement 2 if and only if it satisfies both (A.8) and (A.15). The integer that satisfies both equations is the integer closest to

$$
\sqrt{\frac{g-p e}{2 K}}
$$

Q.E.D. 


\section{Proof of Proposition 5.}

In order to prove Proposition 5 we first need to prove a Lemma. Define as $d_{1}^{\prime}$ and $d_{2}^{\prime}$ the defense spending in country 1 and 2 after the $\varepsilon$ - perturbation. Remember that $s_{1}^{\prime}=s-\varepsilon, s_{2}^{\prime}=s+\varepsilon$, and that we are assuming that $d_{i} \quad i=3, \ldots N$ remain unchanged, so that $d_{i}=\frac{s(1-s) p e}{2} \equiv d$.

\section{Lemma:}

$$
d_{1}^{\prime}<d_{2}^{\prime} ; \quad \frac{d_{1}^{\prime}}{s_{1}^{\prime}}>\frac{d_{2}^{\prime}}{s_{2}^{\prime}}>0
$$

Proof. Using the first order conditions, (10), after some algebra, one obtains the following system of equations in $d_{1}^{\prime}$ and $d_{2}^{\prime}$ :

$$
\begin{aligned}
& (s+\varepsilon)\left[(1-2 s) \frac{d}{\left(d_{2}^{\prime}+d\right)^{2}}+(s-\varepsilon) \frac{d_{1}^{\prime}}{\left(d_{1}^{\prime}+d_{2}^{\prime}\right)^{2}}\right]=\frac{1}{2 p e} \\
& (s-\varepsilon)\left[(1-2 s) \frac{d}{\left(d_{1}^{\prime}+d\right)^{2}}+(s+\varepsilon) \frac{d_{2}^{\prime}}{\left(d_{1}^{\prime}+d_{2}^{\prime}\right)^{2}}\right]=\frac{1}{2 p e}
\end{aligned}
$$

Differentiate both sides with respect to $\varepsilon$, noting that the right hand side of (A.16) and (A.17) are a constant. Then evaluate the two expressions at $\varepsilon=0$, noting that at $\varepsilon=0 \quad d_{1}^{\prime}=d_{2}^{\prime}=d$.

We obtain: 


$$
\begin{gathered}
{\left[\frac{1-2 s}{4 d}+\frac{s}{4 d}\right]+s\left[-\frac{(1-2 s)}{4 d^{2}} \frac{\partial d_{2}^{\prime}}{\partial \varepsilon}-\frac{1}{4 d}-s \frac{\frac{\partial d_{2}^{\prime}}{\partial \varepsilon}}{4 d^{2}}\right]=0} \\
{\left[-\frac{(1-2 s)}{4 d}+\frac{s}{4 d}\right]+s\left[-\frac{(1-2 s)}{4 d^{2}} \frac{\partial d_{1}^{\prime}}{\partial \varepsilon}-\frac{1}{4 d}-s \frac{\frac{\partial d_{1}^{\prime}}{\partial \varepsilon}}{4 d^{2}}\right]=0}
\end{gathered}
$$

Solving, one obtains:

$$
\begin{gathered}
\frac{\partial d_{2}^{\prime}}{\partial \varepsilon}=\frac{1-2 s}{1-s} \frac{d}{s} \\
\frac{\partial d_{1}^{\prime}}{\partial \varepsilon}=-\frac{1-2 s}{1-s} \frac{d}{s}
\end{gathered}
$$

For $s<\frac{1}{2}$ (A20) is positive and (A21) is negative. Using (A20) and (A21), and evaluating at $\varepsilon=0$ one obtains:

$$
\begin{gathered}
\frac{\partial d_{2}^{\prime} / s_{2}^{\prime}}{\partial \varepsilon}=\frac{1}{s+\varepsilon}\left[\frac{\partial d_{2}^{\prime}}{\partial \varepsilon}-\frac{d_{2}^{\prime}}{s+\varepsilon}\right]=-\frac{d}{s(1-s)}=-\frac{p e}{2}<0 \\
\frac{\partial d_{1}^{\prime} / s_{1}^{\prime}}{\partial \varepsilon}=\frac{1}{s-\varepsilon}\left[\frac{\partial d_{1}^{\prime}}{\partial \varepsilon}-\frac{d_{1}^{\prime}}{s-\varepsilon}\right]=\frac{d}{s(1-s)}=\frac{p e}{2}>0
\end{gathered}
$$

Equations (A20), (A21), (A22) and (A23) imply the Lemma. Q.E.D. 
In words, for a small perturbation of the border between two countries, total defense is larger in the larger country, but defense per capita, thus taxes per capita are higher in the smaller country. We are now ready to prove the Proposition.

Define $\tilde{s}(0)$ as the minimum stable size, for $p=0$. From the results of Alesina and Spolaore (1995) we know that for $p=0, \tilde{s}(0)=1 / \tilde{N}$, where $\tilde{N}$ is the largest integer smaller than $\sqrt{\frac{g}{2 K}}$. First, we want to prove that $\hat{s}(p) \geq \hat{s}(0)$ for any $p>0$. If $p=0$ the condition for stability can be written as follows:

$$
g\left(\frac{s-\varepsilon}{2}\right)-\frac{K}{s-\varepsilon}<g\left(\frac{s+\varepsilon}{2}\right)+\frac{K}{s+\varepsilon}
$$

Suppose now that $\hat{s}(p)<\hat{s}(0)$. For some $p>0$, choose $s^{\prime}$ such that $\hat{s}(p)<s^{\prime}<\hat{s}(0)$. Consider the $\varepsilon$ perturbation when $s=s^{\prime}$. Since $s^{\prime}<\hat{s}(0)$ if $p=0$ the individual at the new border prefers the bigger country. Since $s^{\prime}>\hat{s}(p)$ for $p>0$ the border individual prefers the smaller country. This is a contradiction, since if $p>0$ defense pro capita, thus taxes per capita, are higher in the smaller country and total defense, thus the expected revenue from conflict, are lower in the smaller country. Thus if the individual at the border between countries of size $s^{\prime}+\varepsilon$ and $s^{\prime}-\varepsilon$ prefers the bigger country for $p=0$ he cannot prefer the smaller country for $p>0$. Thus, $\hat{s}(p) \geq \hat{s}(0)$ for $p>0$. Consider now $p^{\prime}>p$. A similar argument based on contradiction establishes that $\hat{s}\left(p^{\prime}\right) \geq s(p)$; thus it follows that the function $\hat{s}(p)$ is weakly increasing in $p$. Q.E.D. 


\section{Numerical simulations}

\section{$\underline{\mathcal{E}}$ - Stability.}

Consider $N$ countries of equal size $s=1 / N$. Suppose that a small perturbation takes place at the border between country 1 and country 2 , so that $s_{1}^{\prime}=s-\varepsilon$ and $s_{2}^{\prime}=s+\varepsilon$. The other $N-2$ countries remain of size $s$. All countries adjust their defense spending after the perturbation. New defense spending in country 1 (2) will be denoted by $d_{1}^{\prime}\left(d_{2}^{\prime}\right)$. Defense spending in the remaining $N-2$ countries is denoted by $d^{\prime}$. Then, $d_{1}^{\prime}, d_{2}^{\prime}$ and $d^{\prime}$ are given as follows:

$$
\begin{aligned}
& d_{1}^{\prime}=\operatorname{argmax}\left\{2 p e(s+\varepsilon) \frac{d_{1}^{\prime}}{d_{1}^{\prime}+d_{2}^{\prime}}+2 p e(N-2) s \frac{d_{1}^{\prime}}{d_{1}^{\prime}+d^{\prime}}-\frac{d_{1}^{\prime}}{s-\varepsilon}\right\} \\
& d_{2}^{\prime}=\operatorname{argmax}\left\{2 p e(s-\varepsilon) \frac{d_{2}^{\prime}}{d_{1}^{\prime}+d_{2}^{\prime}}+2 p e(N-2) s \frac{d_{2}^{\prime}}{d_{2}^{\prime}+d^{\prime}}-\frac{d_{2}^{\prime}}{s+\varepsilon}\right\} \\
& d^{\prime}=\operatorname{argmax}\left\{2 p e(s-\varepsilon) \frac{d^{\prime}}{d_{1}^{\prime}+d^{\prime}}+2 p e(s+\varepsilon) \frac{d^{\prime}}{d_{2}^{\prime}+d^{\prime}}+2 p e(N-3) s \frac{d^{\prime}}{d^{\prime}+\bar{d}^{\prime}}-\frac{d^{\prime}}{s}\right\}
\end{aligned}
$$

The first-order conditions are: 


$$
\begin{gathered}
2 p e(s+\varepsilon) \frac{d_{2}^{\prime}}{\left(d_{1}^{\prime}+d_{2}^{\prime}\right)^{2}}+2 p e(1-2 s) \frac{d^{\prime}}{\left(d_{1}^{\prime}+d^{\prime}\right)^{2}}=\frac{1}{s-\varepsilon} \\
2 p e(s-\varepsilon) \frac{d_{1}^{\prime}}{\left(d_{1}^{\prime}+d_{2}^{\prime}\right)^{2}}+2 p e(1-2 s) \frac{d^{\prime}}{\left(d_{1}^{\prime}+d^{\prime}\right)^{2}}=\frac{1}{s+\varepsilon} \\
2 p e(s-\varepsilon) \frac{d_{1}^{\prime}}{\left(d_{1}^{\prime}+d^{\prime}\right)^{2}}+2 p e(s+\varepsilon) \frac{d_{2}^{\prime}}{\left(d_{2}^{\prime}+d^{\prime}\right)^{2}}+2 p e(1-3 s) \frac{1}{4 d^{\prime}}=\frac{1}{s}
\end{gathered}
$$

For any given vector of parameters $(p e, g, K)$ and for any given configuration of $N$ countries of size $s=1 / N$, it is possible to calculate the amount of defense per capita,

$$
\hat{d}_{1}^{\prime}=d_{1}^{\prime} /(s-\varepsilon), \hat{d}_{2}^{\prime}=d_{2}^{\prime} /(s+\varepsilon), \hat{d}_{3}^{\prime}=d^{\prime} / s
$$

that would be chosen, respectively, in country 1 , country 2 , and in the remaining N-2 countries when the border between country 1 and country 2 is perturbated, so that a fraction $\varepsilon=\lambda s$ of the population of country 1 joins country 2 , where $\lambda$ is a number much smaller than 1 . These values can be obtained by solving the system (A-25)-(A-27) numerically. Table 1 shows the values of $\hat{d}_{1}^{\prime}, \hat{d}_{2}^{\prime}$, and $\hat{d}_{3}^{\prime}$, for $p e=500$.

By using the above defense values, we can then calculate the utility $u_{1}^{\prime}\left(u_{2}^{\prime}\right)$ of the individual at the border between country 1 and country 2 if she belongs to country 1 (country 
2). In general, these utilities are given as follows:

$$
\begin{aligned}
u_{1}^{\prime}=[1-p(1-(s-\varepsilon))] & e+2 p e\left[(s+\varepsilon) \frac{d_{1}^{\prime}}{d_{1}^{\prime}+d_{2}^{\prime}}+(1-2 s) \frac{d_{1}^{\prime}}{d_{1}^{\prime}+d^{\prime}}\right]-\frac{K}{s-\varepsilon} \\
& -\frac{d_{1}^{\prime}}{s-\varepsilon}-g \frac{s-\varepsilon}{2} \\
u_{2}^{\prime}= & {[1-p(1-(s+\varepsilon))] e } \\
+2 p e[(s-\varepsilon) & \left.\frac{d_{2}^{\prime}}{d_{1}^{\prime}+d_{2}^{\prime}}+(1-2 s) \frac{d_{2}^{\prime}}{d_{2}^{\prime}+d}\right]-\frac{K}{s+\varepsilon} \\
& -\frac{d_{2}^{\prime}}{s+\varepsilon}-g \frac{s+\varepsilon}{2}
\end{aligned}
$$

The values of $u_{1}^{\prime}$ and $u_{2}^{\prime}$ are reported in Tables 1 and 2 for different values of $g$ and $K$. If $u_{1}^{\prime}>u_{2}^{\prime}$, the individual at the border would like to join the smaller country. In this case, the original configuration would be stable. By contrast, if $u_{1}^{\prime}<u_{2}^{\prime}$, the individual at the border would like to join the larger country, henceforth amplifying the perturbation. In the latter case, the original configuration is not stable (i.e., it does not satisfy Requirement 3). Tables 1 and 2 indicate with " 1 " whether $u_{1}^{\prime}>u_{2}^{\prime}$, (stability) and with " 0 " the opposite case (instability), for different values of $g$, when $p e=500$ and $K=0.5$ (Table 1 ) and $K=4$ (Table 2).

For any given value of the vector $(p e, g, K)$, we can then find the maximum $N$ that satisfies Requirement 3, i.e., that is stable (note that if $N$ is stable, so is $N-1$ ). Let $N^{\varepsilon}$ denote the maximum number of equally-sized countries that satisfies Requirement 3, i.e., that is stable (or, more specifically, $\varepsilon$-stable). 
Table 3 shows the values of $N^{\mathrm{e}}$ for different values of the parameters $(p e, g, K)$. Denote with $N^{\prime}$ the largest integer smaller than $\sqrt{\frac{g-p e}{2 K}}$, and with $N^{\prime \prime}$ the integer that is closest to $\sqrt{\frac{g-p e}{2 K}}$. It is immediate to notice that:

1) $\quad N^{\epsilon}$ is decreasing in pe. This result is illustrated in Figures 1-4 for selected values of $g$ and $K$.

2) $\quad N^{\prime}$ is always $\varepsilon$-stable; $N^{\prime \prime}$ is $\varepsilon$-stable for values of $p e$ larger than the critical value $\overline{p e}$ defined by the following equation: ${ }^{14}$

$$
N^{\mathrm{e}}(\overline{p e})=\sqrt{\frac{g-\overline{\overline{p e}}}{2 K}}
$$

Hence, if $N^{\prime \prime}$ is $\varepsilon$-stable, the number $N$ which satisfies Requirement 2 ' is equal to $N^{\prime \prime}$. Otherwise, it is equal to $N^{\prime}$, which is always stable.

\section{Secession-Free Equilibria}

Consider $N$ countries of equal size $s$. Consider a secession of size $\mathrm{z}$ taking place in country 1 . Then, we have a new country of size z spending $d_{z}$ in defense. The rest of country 1 , being now of size $s-z$, spending $d_{s-z}$ in defense, and the remaining $N-1$ countries,

${ }^{14}$ For instance, in table $3(K=0.5)$, for $g=800$, the critical $\overline{p e}$ is 400 ; for $g=1600$, the critical $\overline{p e}$ is 700 , etc. 
of size $s=1 / N$, spending $d^{\prime}$ in defense. $d_{z}, d_{s-z}$ and $d^{\prime}$ are given by the following first order conditions (as long as the system has strictly positive solutions) ${ }^{15}$ :

$$
\begin{gathered}
2 p e(s-z) \frac{d_{s-z}}{\left(d_{z}+d_{s-z}\right)^{2}}+2 p e(1-s) \frac{d^{\prime}}{\left(d_{z}+d^{\prime}\right)^{2}}=\frac{1}{z} \\
2 p e z \frac{d_{z}}{\left(d_{z}+d_{s-z}\right)^{2}}+2 p e(1-s) \frac{d^{\prime}}{\left(d_{s-z}+d^{\prime}\right)^{2}}=\frac{1}{s-z} \\
2 p e z \frac{d_{z}}{\left(d_{z}+d^{\prime}\right)^{2}}+2 p e(s-z) \frac{d_{s-z}}{\left(d_{s-z}+d^{\prime}\right)^{2}}+\frac{2 p e(1-s)}{4 d^{\prime}}=\frac{1}{s}
\end{gathered}
$$

For any $z \leq s / 2$, let $u_{n}$ denote the status-quo utility of an individual located at a distance $\mathrm{s} / 2-\mathrm{z}$ from the center, that is:

$$
u_{n}=e+g\left(1-\left(\frac{s}{2}-z\right)\right)-\frac{K}{s}-\frac{d^{*}}{s}
$$

Let $u_{s}$ denote the utility of that same individual should a secession of size $\mathrm{z}$ occur, so that he would be located at the border between the new country of size $\mathrm{z}$ and the rest of his old country, now of size s-z:

$$
\begin{aligned}
u_{s} & =p(s-z) \frac{d_{z}}{d_{z}+d_{s-z}} 2 e+p(N-1) s \frac{d_{z}}{d_{z}+d^{\prime}} 2 e \\
& +(1-p(1-z)) e+g\left(1-\frac{z}{2}\right)-\frac{K}{z}-\frac{d_{z}}{z}
\end{aligned}
$$


This individual would be in favor of (against) a unilateral secession of size $\mathrm{z}$ as long as $u_{n}$ is smaller (larger) than $u_{s}$, and be indifferent in the case $u_{n}=u_{s}$. For a given configuration of $N$ countries of size $s=1 / N$, we can calculate the values of $u_{n}$ and $u_{s}$ associated with different possible secessions of size $z=\lambda s$, where $\lambda$ takes different values between 0 and 0.5 . Similar calculations, mutatis mutandis, can be performed for values of $\lambda$ larger than 0.5 . If $u_{n}$ is smaller than $u_{s}$ for some values of $\lambda$, that configuration will not be secession free. On the other hand, if for every $\lambda u_{n} \geq u_{s}$, we can say that $s=1 / \mathrm{N}$ is secession-free.

Table 4 shows the values of defense per capita and of $u_{n}$ and $u_{s}$ for $\mathrm{g}=800, \mathrm{~K}=0.5$, and pe $=50$. The $\lambda^{\prime} s$ take values between .05 and $.5^{16}$ In this example, $s=1 / 2$ and $s=1 / 3$ $(\mathrm{N}=2$ and $\mathrm{N}=3$ ) are not secession free. Up to $25 \%$ of the citizens of each country of size $\mathrm{s}$ would be happier if they could form a smaller country on their own. Secessions of size $1 / 40,1 / 20,15 / 200,1 / 10$ and $1 / 8$ would all be approved unanimously by the relevant subset of citizens. $s=1 / 4(N=4)$ is not secession-free either, because up to $20 \%$ of the citizens of each country of size s would like to form a smaller country. $N=5$ is not secession free because secessions of size $z=s / 10=1 / 50$ and $z=.15 s=3 / 100$ would be unanimously preferred by the relevant fractions of the population. By contrast, values of $\mathrm{N}$ larger than 5 are secession free.

\footnotetext{
${ }^{16}$ For this specific example, no secession would ever occur for $\lambda>0.5$. This turns out to be true in all our calculations for $\mathrm{N}>2$. In some cases, when $\mathrm{N}=2$, a majority of the original population may want to secede and form a smaller nation.
} 
In general, if $\mathrm{N}$ is secession-free, so is $\mathrm{N}+1$. For each value of the parameters $(\mathrm{g}, \mathrm{K}$, pe), we can calculate the minimum $\mathrm{N}$ that is secession-free. In Tables 5 and 6 , the minimum $\mathrm{N}$ that is secession free is denoted by $N^{\lambda}$, and is calculated for different values of the parameters. In particular, we find that:

- $N^{\lambda}$ is decreasing in pe. This result is illustrated in Figures 5 - 7.

- The largest integer smaller than $\sqrt{\frac{g-p e}{2 K}}$ is always secession free. 


\section{References}

Alesina, A., R. Perotti and E. Spolaore (1995), "Together or Separately? Issues on the Costs and Benefits of Political and Fiscal Unions," European Economic Review, April.

Alesina, A., and E. Spolaore (1995), "On the Number and Size of Nations," NBER Working Paper No. 5050, March. Revised: October.

Bolton, P., G. Roland (1995), "The Break-up of Nations: A Political Economy Analysis," CEPR Discussion Paper No. 1225, August.

Bolton, P., G. Roland and E. Spolaore (1996), "Economic Theories of the Break-up and Integration of Nations," European Economic Review, April.

Boulding, K.E. (1962), Conflict and Defense: A General Theory, Harper, New York.

Casella, A., and J. Feinstein (1990), "Public Goods in Trade: On the Formation of Markets and Political Jurisdictions," NBER Working Paper No. 3554, December.

Friedman, D. (1977), "A Theory of the Size and Shape of Nations," Journal of Political Economy, 85 (1).

Garfinkel, M.R. (1994), "Domestic Politics and International Conflict," American Economic Review, December.

Hirshleifer, J. (1989), "Conflict and Rent-Seeking Success Functions: Ratio versus Difference Models of Relative Success," Public Choice, November.

(1991), "The Technology of Conflict as an Economic Activity," American Economic Review Papers and Proceedings, May.

(1995), “Anarchy and Its Breakdown," Journal of Political Economy, Vol. 103, February.

Olson, M., and R. Zeckhauser (1966), "An Economic Theory of Alliances," Review of Economics and Statistics, 48, 266-79.

Sachs and Sala-i-Martin (1992), "Fiscal Federalism and Optimum Currency Areas: Evidence for Europe from the United States," in: M. Canzoneri, P. Masson and V. Griles (eds.), 
Establishing a Central Bank: Issues in Europe and Lessons from the U.S., Cambridge University Press, Cambridge and New York.

Sandler, T. And K. Hartley, (1995), The Economics of Defense, Cambridge University Press, New York.

Schelling, T.C. (1960), The Strategy of Conflict, Harvard University Press, Cambridge (MA).

Spolaore, E. (1995a), "Enlargements Dynamics in Political and Economic Unions," Yrjö Jahnsson European Integration Lectures 7, October.

(1995b), "Economic Integration and Political Borders," prepared for the conference "Regional Integration and Economic Growth," Tel Aviv University.

Tullock, G. (1974), The Social Dilemma: The Economics of War and Revolution, University Pub., Blacksburg (VA).

(1980), "Efficient Rent Seeking," in Toward a Theory of the Rent-Seeking Society, edited by J.M. Buchanan, R.D. Tollison, and G. Tullock, Texas A\&M University Press, College Station.

Wei, Shang-Jin (1992), "To Divide or to United: A Theory in Secessions," mimeo, University of California, Berkeley.

Wilson, E.O. (1980), "Sociobiology," Harvard University Press, Cambridge. 


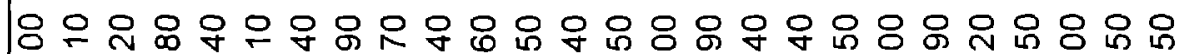

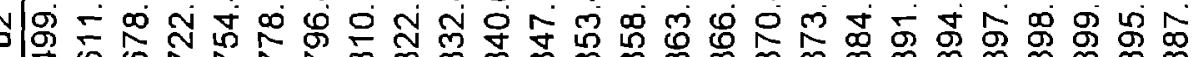
莳 웅 క

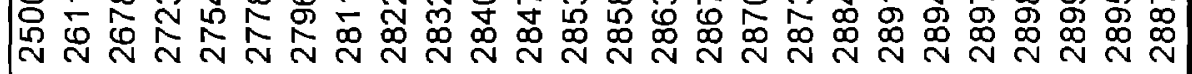

บับ

$\frac{\widehat{\Lambda}}{3}$

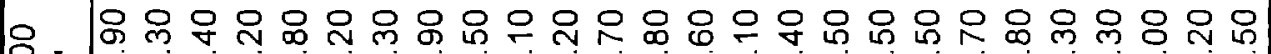

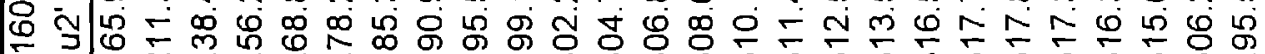
II

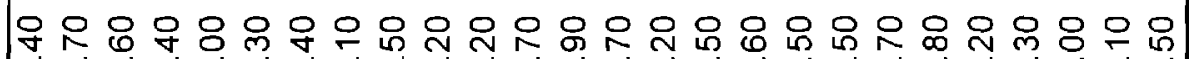
うழ

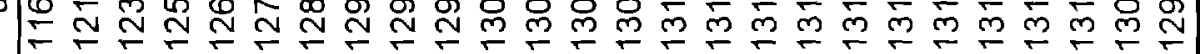
곡

$\stackrel{\hat{H}}{\leftrightarrows}$

8- б行 I II O 6 \%

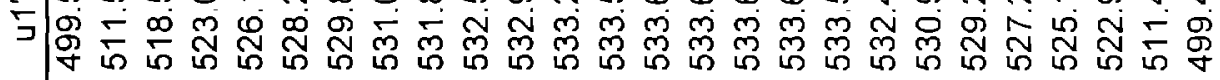
극 $\frac{\hat{T}}{\mathrm{~T}}-000000000000000000000000$

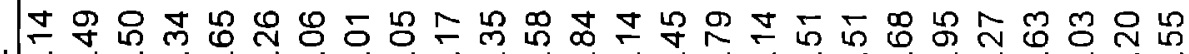
粦 은

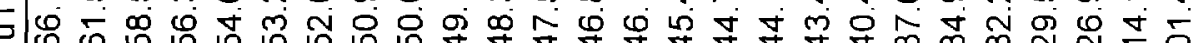

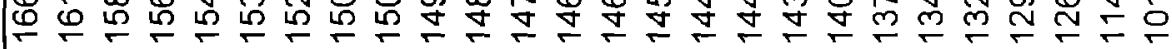
6

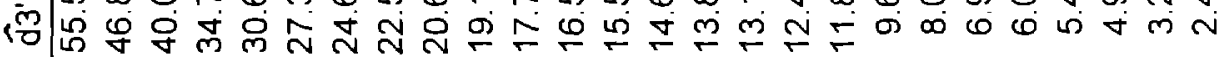

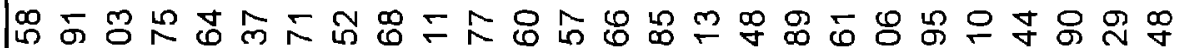

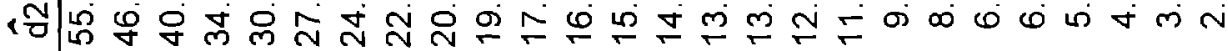

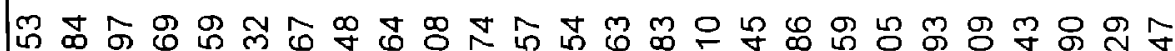

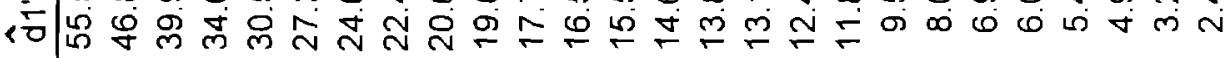

题

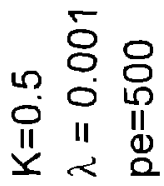
(艹)

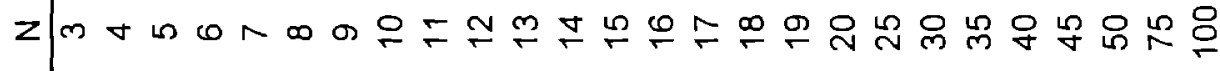




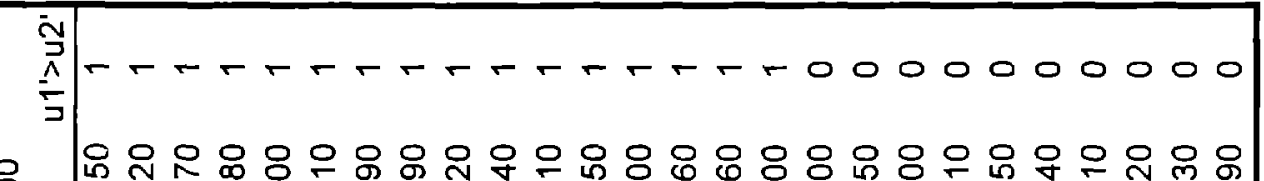

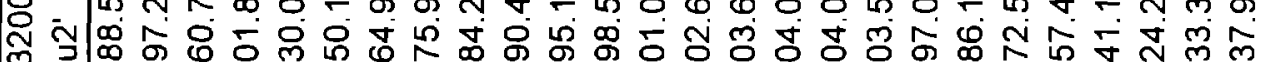
II

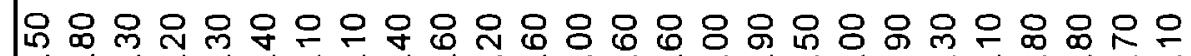
うळ N

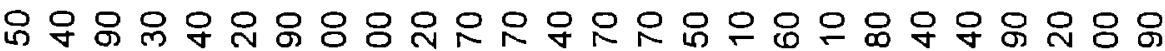

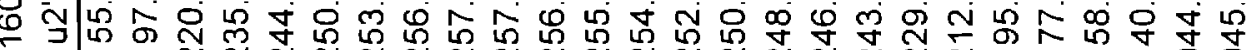

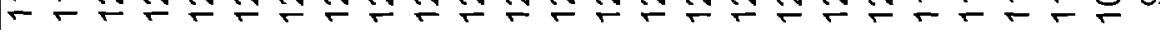

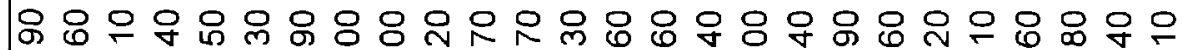

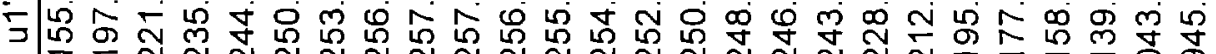

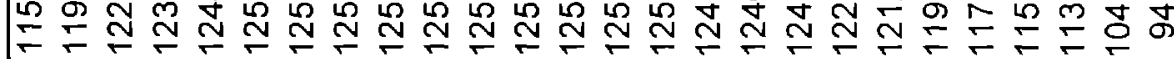

thr-

๙

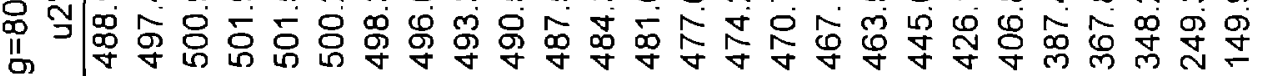

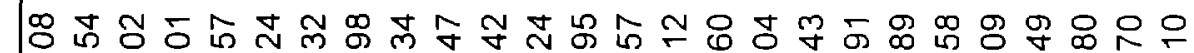

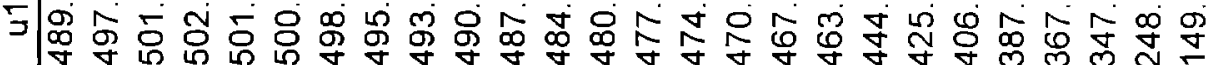
긴 1 -0000000000000000000000000 $\stackrel{ }{5}$

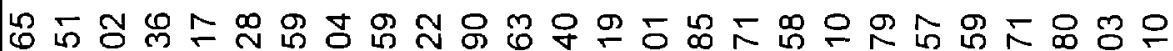

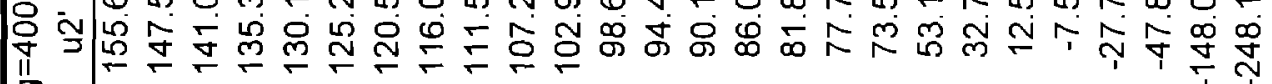
II

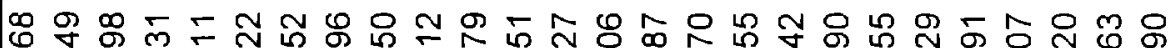

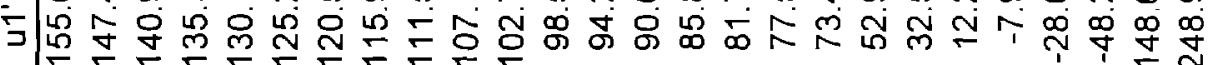

0 م $N$ N

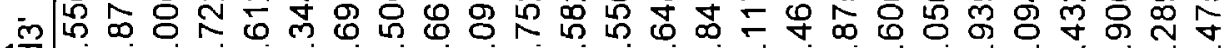

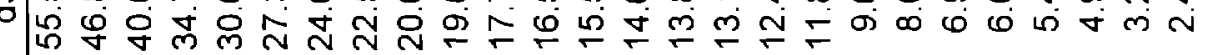

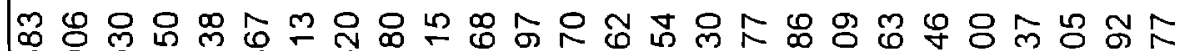

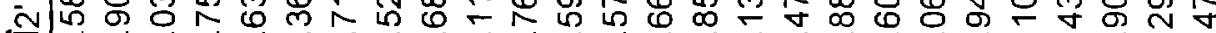

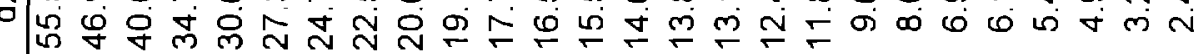

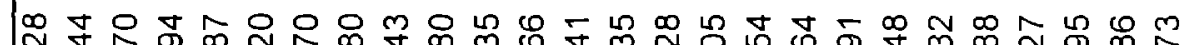

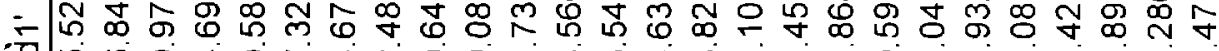

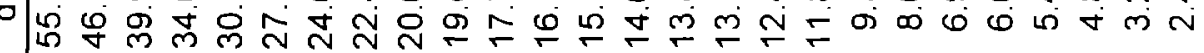

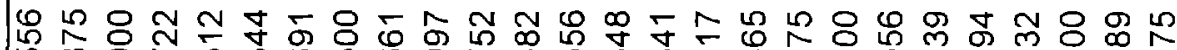
*

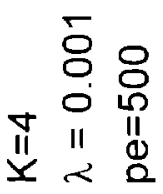




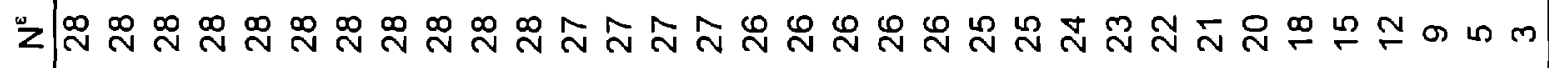
号

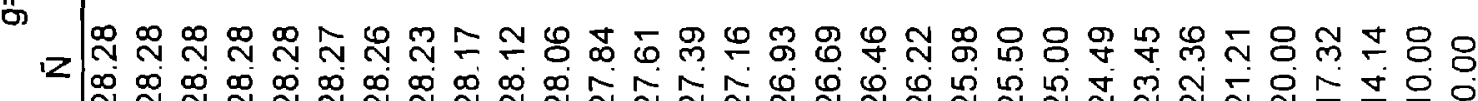

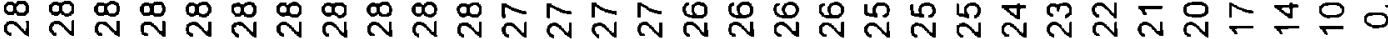

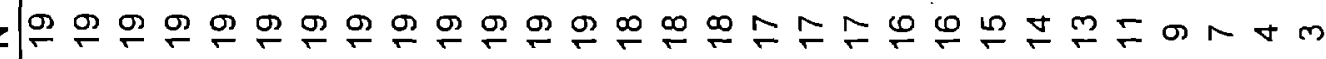
용 min

용 岤

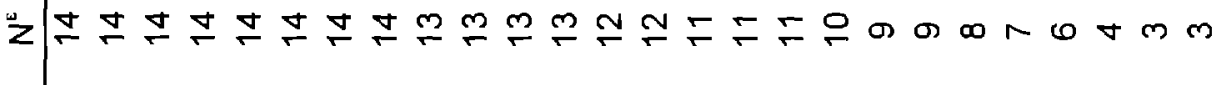
$\stackrel{8}{\circ}$

の

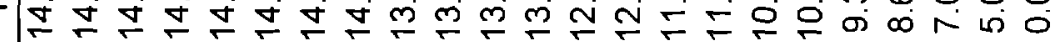

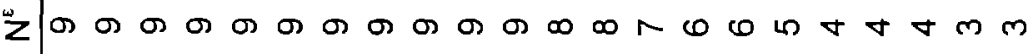

要

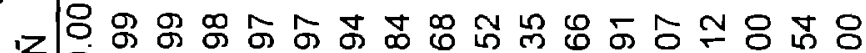

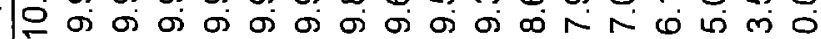

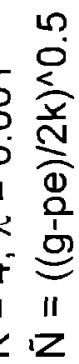

夏

$z \hat{z}$

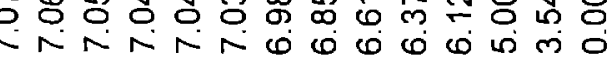

*”융 


\begin{tabular}{|c|c|c|c|c|c|c|c|c|c|c|c|}
\hline & & $\lambda=.05$ & $\lambda=.10$ & $\lambda=.15$ & $\lambda=.20$ & $\lambda=.25$ & $\lambda=.30$ & $\lambda=.35$ & $\lambda=.40$ & $\lambda=.45$ & $\lambda=.50$ \\
\hline \multirow{7}{*}{$\mathbf{N}=\mathbf{2}$} & $\hat{\mathrm{d}}^{*}$ & 12.5 & 12.5 & 12.5 & 12.5 & 12.5 & 12.5 & 12.5 & 12.5 & 12.5 & 12.5 \\
\hline & $a_{1}$ & 0 & 0 & 8.29 & 14.50 & 17.35 & 18.65 & 19.15 & 19.18 & 18.94 & 18.51 \\
\hline & dि2 & 12.50 & 12.50 & 13.17 & 14.12 & 15.00 & 15.83 & 16.59 & 17.31 & 17.95 & 18.51 \\
\hline & d3 & 11.87 & 11.25 & 11.29 & 11.60 & 11.82 & 11.99 & 12.11 & 12.19 & 12.24 & 12.26 \\
\hline & un & 608 & 628 & 648 & 668 & 688 & 708 & 728 & 748 & 768 & 788 \\
\hline & & 722 & 724 & 719 & 715 & 710 & 704 & 698 & 691 & 684 & 677 \\
\hline & un $\geq$ us & 0 & 0 & 0 & 0 & 0 & 1 & 1 & 1 & 1 & 1 \\
\hline \multirow{7}{*}{$\mathbf{N}=3$} & $\hat{d^{*}}$ & 16.67 & 16.67 & 16.67 & 16.67 & 16.67 & 16.67 & 16.67 & 16.67 & 16.67 & 16.67 \\
\hline & d1 1 & 0 & 0 & 0 & 8.59 & 14.01 & 16.94 & 18.57 & 19.43 & 19.81 & 19.88 \\
\hline & d2 2 & 16.66 & 16.65 & 16.64 & 17.26 & 17.93 & 18.51 & 19.02 & 19.44 & 19.73 & 19.88 \\
\hline & $\widehat{d} 3$ & 16.25 & 15.83 & 15.40 & 15.57 & 15.78 & 15.94 & 16.05 & 16.13 & 16.18 & 16.19 \\
\hline & un & 663 & 676 & 690 & 703 & 716 & 730 & 743 & 756 & 770 & 783 \\
\hline & & 715 & 724 & 724 & 721 & 719 & 717 & 714 & 711 & 707 & 703 \\
\hline & un $\geq$ us & 0 & 0 & 0 & 0 & 0 & 1 & 1 & 1 & 1 & 1 \\
\hline \multirow{7}{*}{$\mathrm{N}=4$} & $\hat{d^{*}}$ & 18.75 & 18.75 & 18.75 & 18.75 & 18.75 & 18.75 & 18.75 & 18.75 & 18.75 & 18.75 \\
\hline & $\hat{d} 1$ & 0 & 0 & 0 & 4.63 & 11.60 & 15.53 & 17.85 & 19.21 & 19.98 & 20.37 \\
\hline & $\mathrm{d} 2$ & 18.74 & 18.73 & 18.69 & 18.91 & 19.42 & 19.85 & 20.18 & 20.40 & 20.48 & 20.37 \\
\hline & d3 & 18.44 & 18.12 & 17.8 & 17.71 & 17.89 & 18.03 & 18.13 & 18.19 & 18.23 & 18.25 \\
\hline & & 690 & 700 & 710 & 720 & 730 & 740 & 750 & 760 & 770 & 780 \\
\hline & & 707 & 722 & 725 & 724 & 723 & 722 & 721 & 720 & 718 & 716 \\
\hline & $u n \geq u s$ & 0 & 0 & 0 & 0 & 1 & 1 & 1 & 1 & 1 & 1 \\
\hline \multirow{7}{*}{$N=5$} & $\hat{d}^{*}$ & 20 & 20 & 20 & 20 & 20 & 20 & 20 & 20 & 20 & 20 \\
\hline & d̂1 & 0 & 0 & 0 & 1.86 & 9.87 & 14.47 & 17.24 & 18.95 & 19.99 & 20.58 \\
\hline & $\hat{\mathrm{d} 2}$ & 19.99 & 19.97 & 19.92 & 19.93 & 20.34 & 20.65 & 20.86 & 20.95 & 20.87 & 20.58 \\
\hline & d3 & 19.75 & 19.49 & 19.23 & 19.04 & 19.21 & 19.33 & 19.41 & 19.47 & 19.51 & 19.52 \\
\hline & un & 706 & 714 & 722 & 730 & 738 & 746 & 754 & 762 & 770 & 778 \\
\hline & & 698 & 719 & 724 & 725 & 725 & 725 & 725 & 725 & 724 & 723 \\
\hline & un $\geq$ us & 1 & 0 & 0 & 1 & 1 & 1 & 1 & 1 & 1 & 1 \\
\hline \multirow{7}{*}{$N=6$} & $\hat{d}^{*}$ & 20.83 & 20.83 & 20.83 & 20.83 & 20.83 & 20.83 & 20.83 & 20.83 & 20.83 & 20.83 \\
\hline & di & 0 & 0 & 0 & 0 & 8.58 & 13.65 & 16.76 & 18.71 & 19.94 & 20.69 \\
\hline & $\hat{\mathrm{d} 2}$ & 20.82 & 20.79 & 20.74 & 20.65 & 20.96 & 21.19 & 21.31 & 21.30 & 21.11 & 20.69 \\
\hline & $\widehat{d} 3$ & 20.62 & 20.41 & 20.19 & 19.97 & 20.11 & 20.21 & 20.29 & 20.35 & 20.38 & 20.39 \\
\hline & un & 717 & 724 & 730 & 737 & 744 & 750 & 757 & 764 & 770 & 777 \\
\hline & us & 688 & 715 & 722 & 724 & 725 & 726 & 727 & 728 & 728 & 727 \\
\hline & 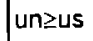 & 1 & 1 & 1 & 1 & 1 & 1 & 1 & 1 & 1 & 1 \\
\hline \multirow{7}{*}{$N=7$} & $\hat{d}^{*}$ & 21.43 & 21.43 & 21.43 & 21.43 & 21.43 & 21.43 & 21.43 & 21.43 & 21.43 & 21.43 \\
\hline & $\hat{d} 1$ & 0 & 0 & 0 & 0 & 7.58 & 13.01 & 16.37 & 18.51 & 19.88 & 20.75 \\
\hline & d̂̀ 2 & 21.42 & 21.39 & 21.32 & 21.22 & 21.42 & 21.58 & 21.63 & 21.54 & 21.27 & 20.75 \\
\hline & $\hat{d} 3$ & 21.25 & 21.07 & 20.88 & 20.69 & 20.77 & 20.86 & 20.93 & 20.98 & 21.01 & 21.02 \\
\hline & un & 725 & 730 & 736 & 742 & 748 & 753 & 759 & 765 & 770 & 776 \\
\hline & & 678 & 711 & 720 & 724 & 725 & 727 & 728 & 729 & 730 & 730 \\
\hline & 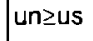 & 1 & 1 & 1 & 1 & 1 & 1 & 1 & 1 & 1 & 1 \\
\hline \multirow{7}{*}{$N=8$} & $\mathrm{~d}^{*}$ & 21.88 & 21.88 & 21.88 & 21.88 & 21.88 & 21.88 & 21.88 & 21.88 & 21.88 & 21.88 \\
\hline & $\hat{d} 1$ & 0 & 0 & 0 & 0 & 6.79 & 12.50 & 16.06 & 18.34 & 19.83 & 20.79 \\
\hline & d̂2 & 21.86 & 21.83 & 21.76 & 21.65 & 21.76 & 21.87 & 21.87 & 21.72 & 21.38 & 20.79 \\
\hline & $\partial \widehat{\partial}$ & 21.72 & 21.56 & 21.39 & 21.22 & 21.27 & 21.35 & 21.42 & 21.46 & 21.49 & 21.50 \\
\hline & un & 730 & 735 & 740 & 745 & 750 & 755 & 760 & 765 & 770 & 775 \\
\hline & us & 669 & 707 & 718 & 722 & 725 & 727 & 729 & 730 & 731 & 732 \\
\hline & un $\geq \mathbf{u s}$ & 1 & 1 & 1 & 1 & 1 & 1 & 1 & 1 & 1 & \\
\hline
\end{tabular}


z 过

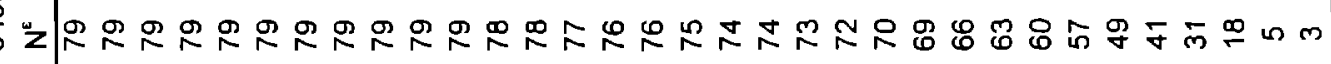

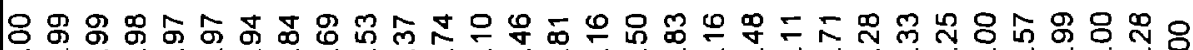

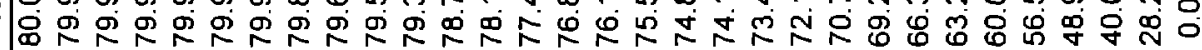

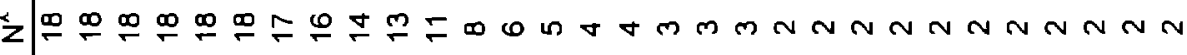

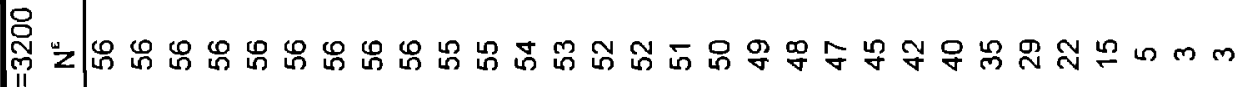

โิ

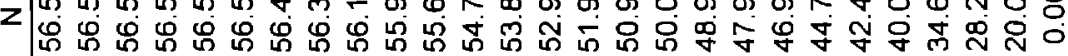

z 兽

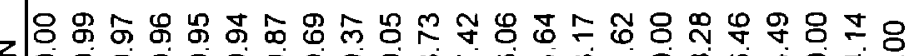

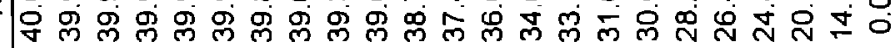

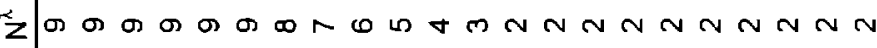

尊

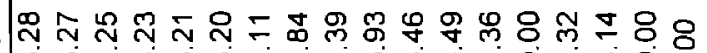

z N

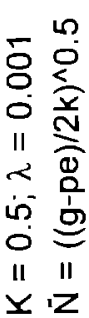

否

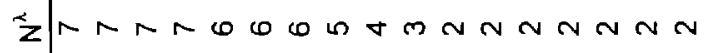

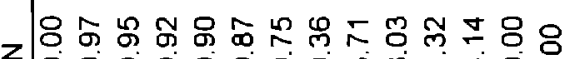

人

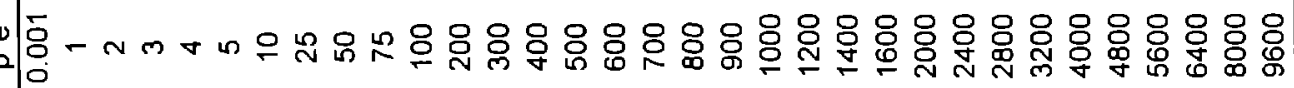


zada a a

蛋 "o

蛋 乙

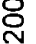

zinhankn.

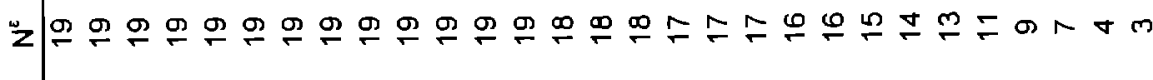

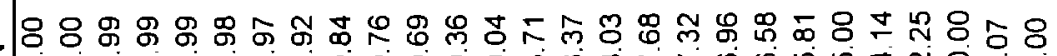

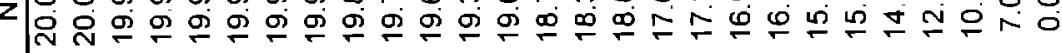

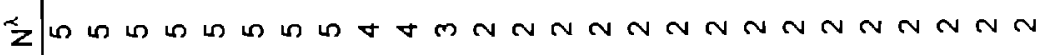

응

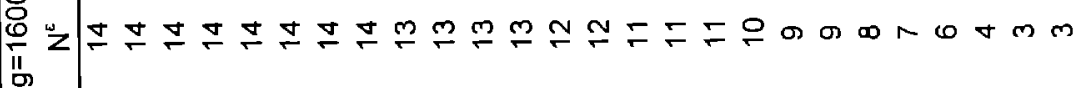

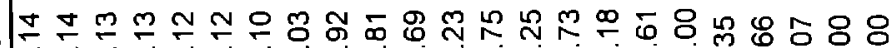

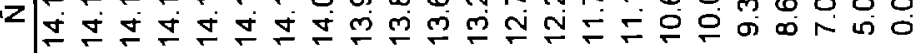

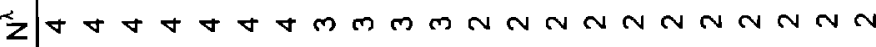

品

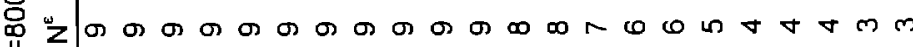

or

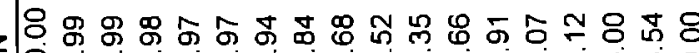

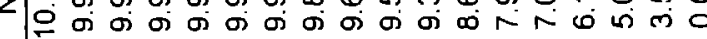

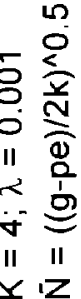

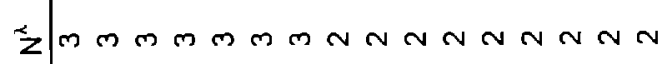

尊坚

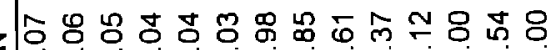

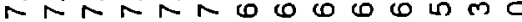

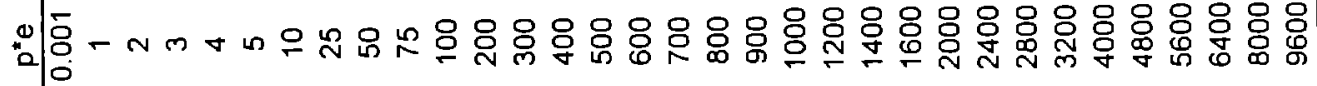




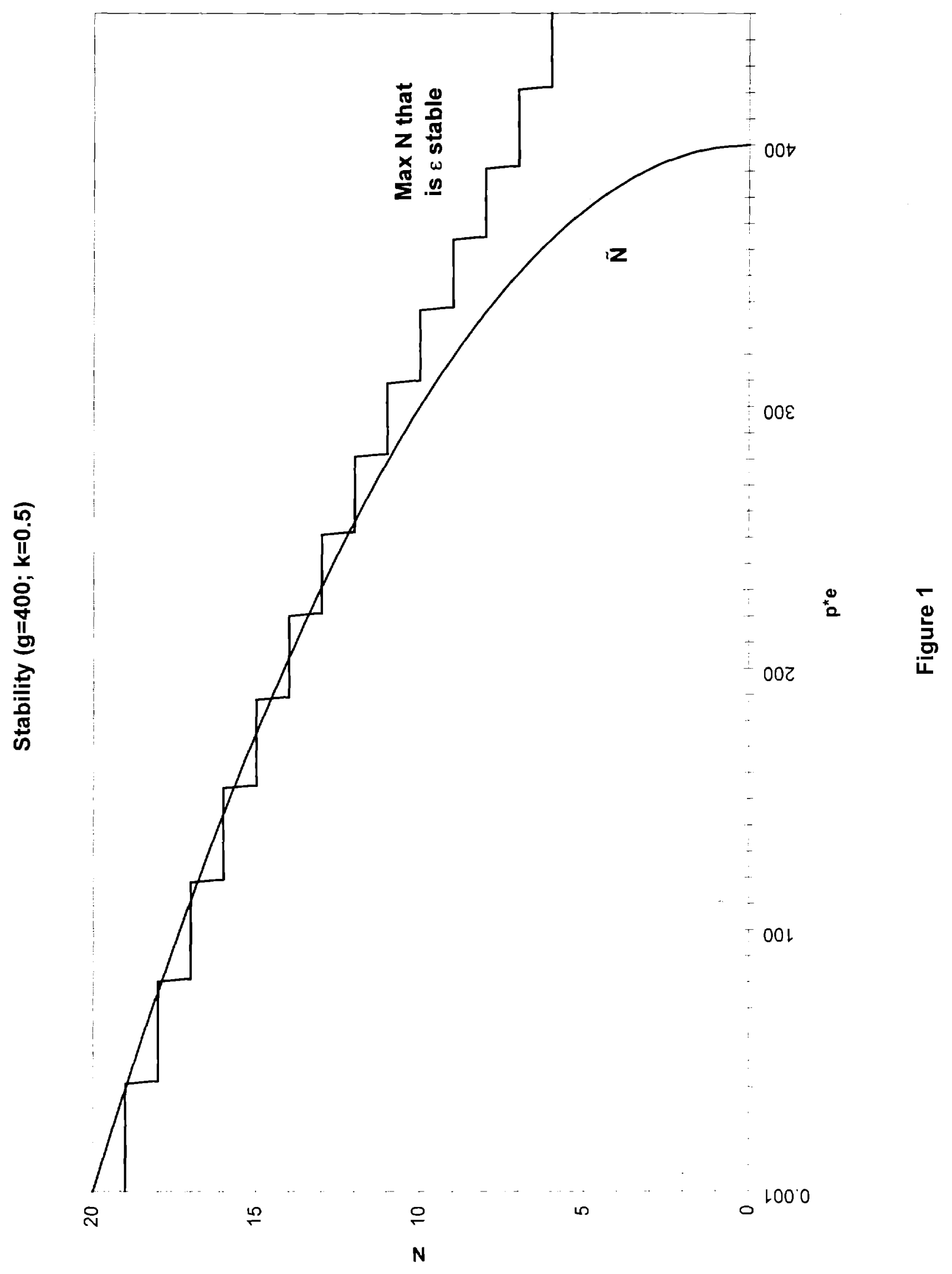




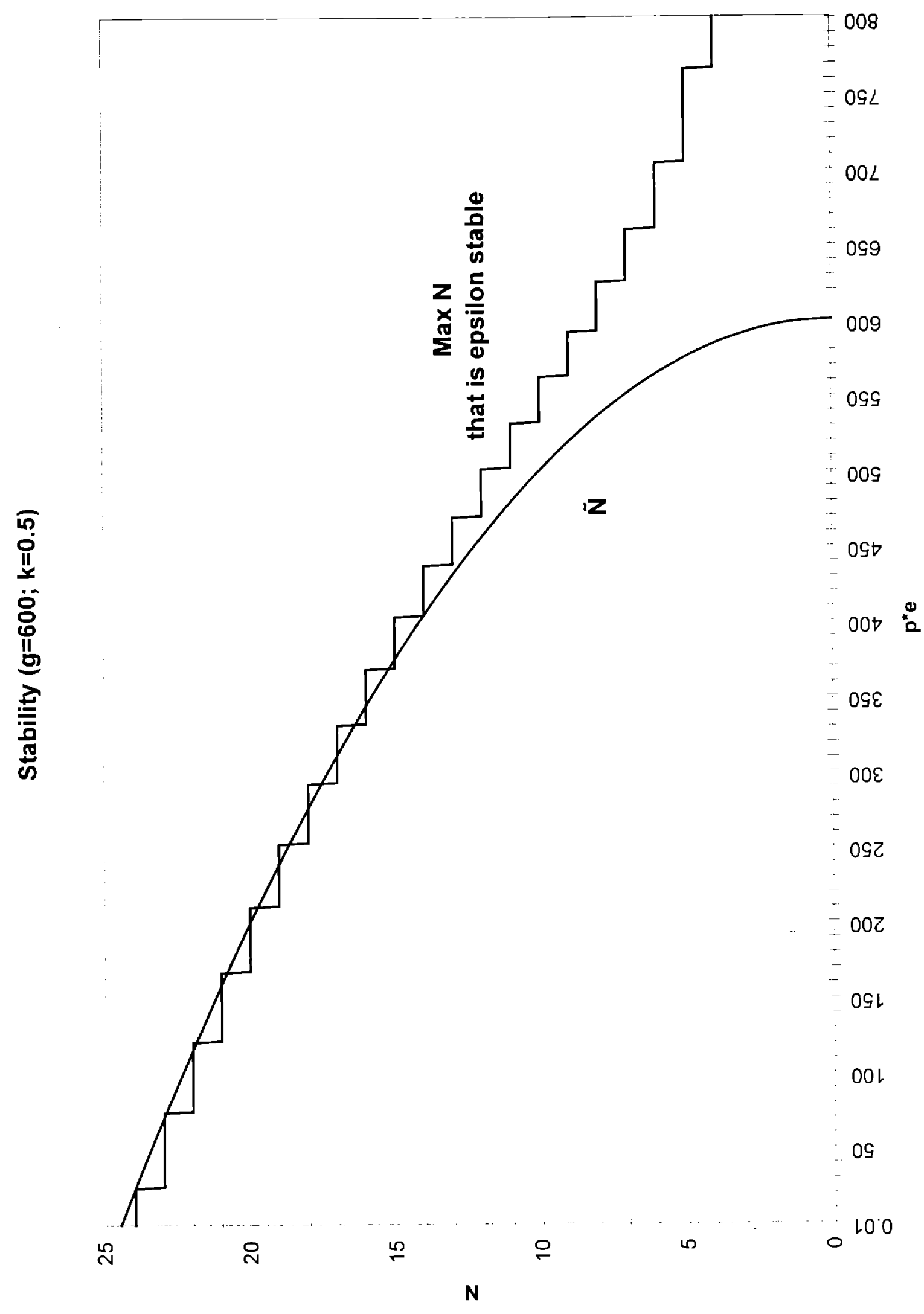




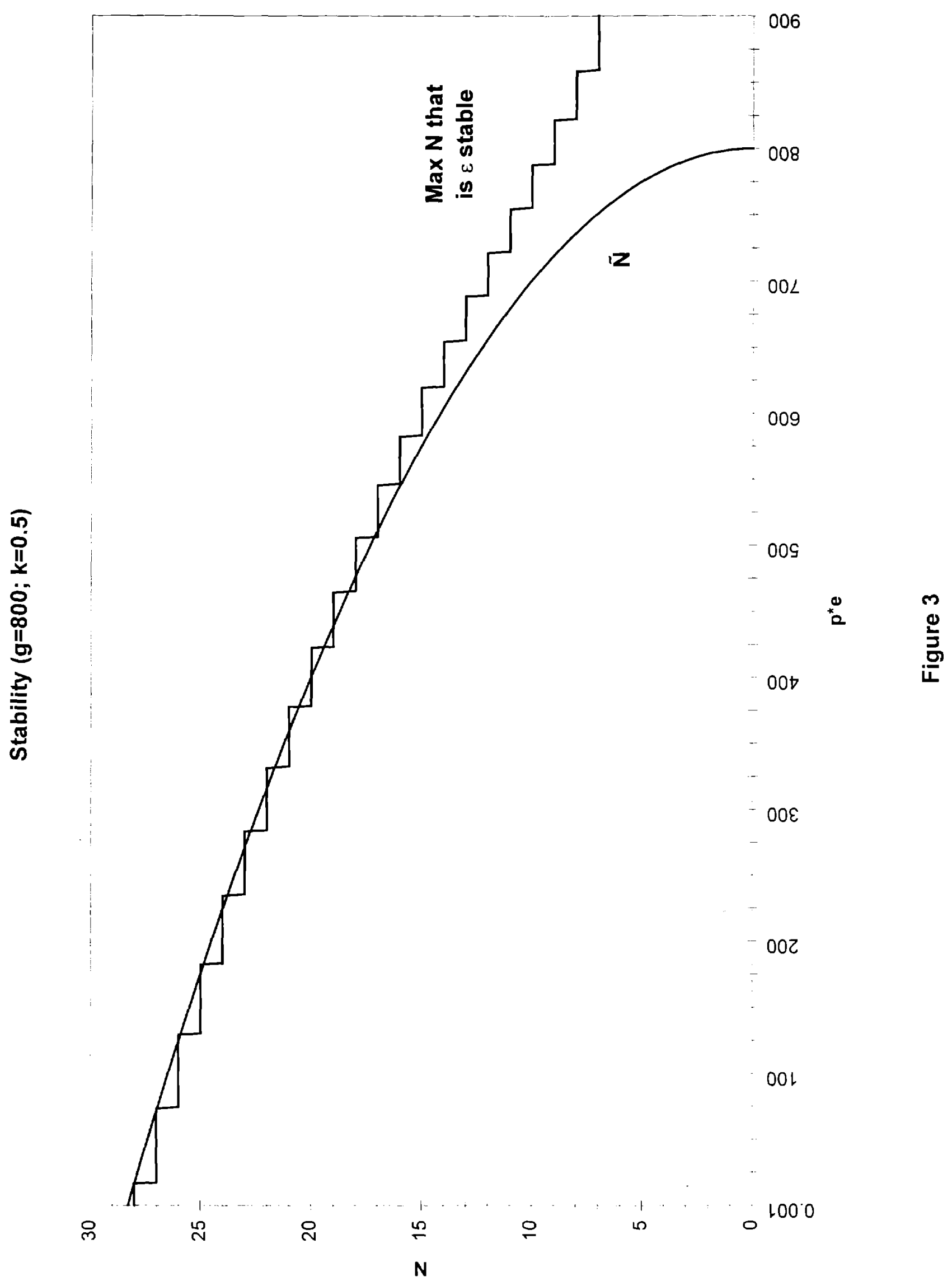




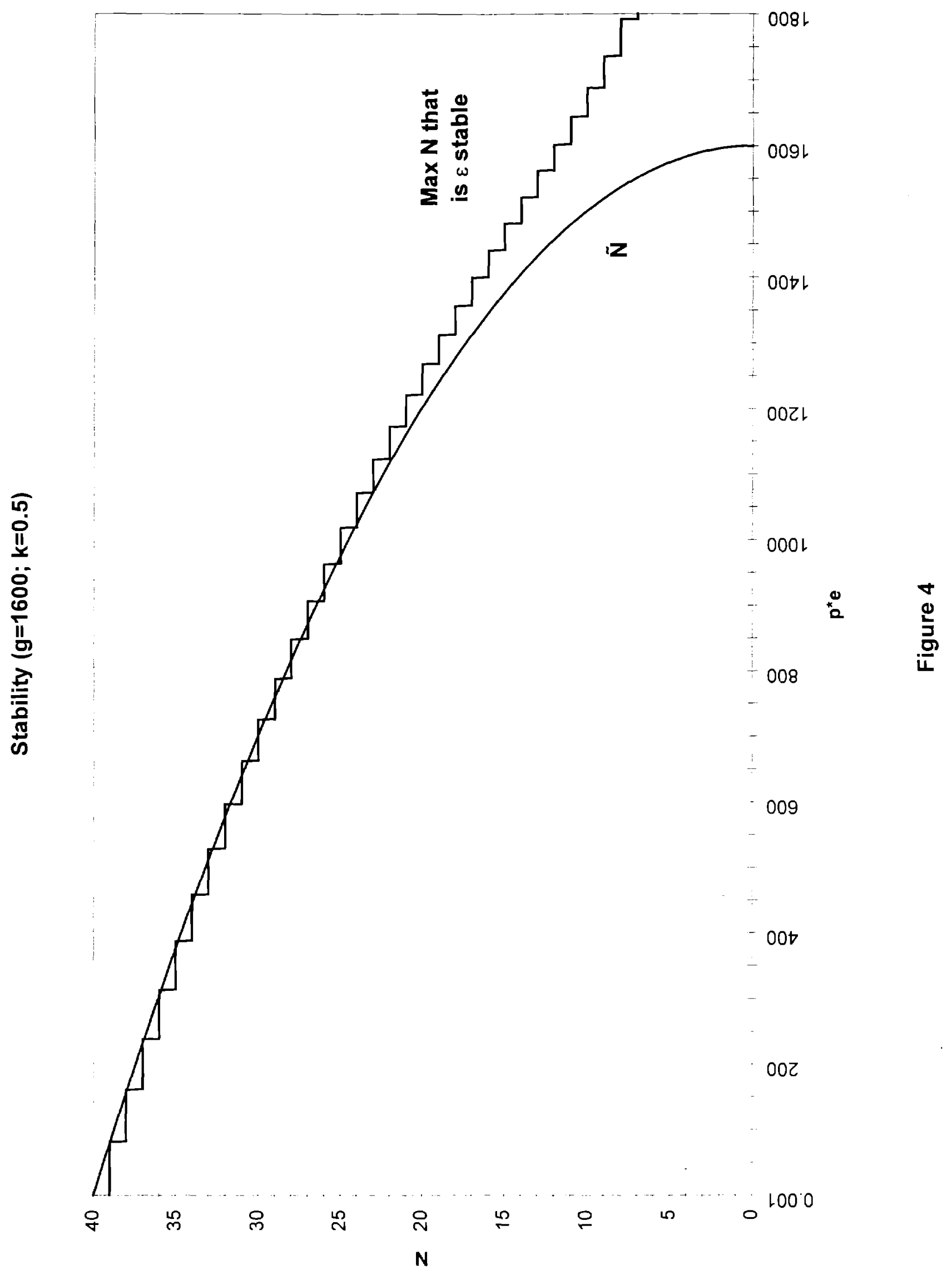




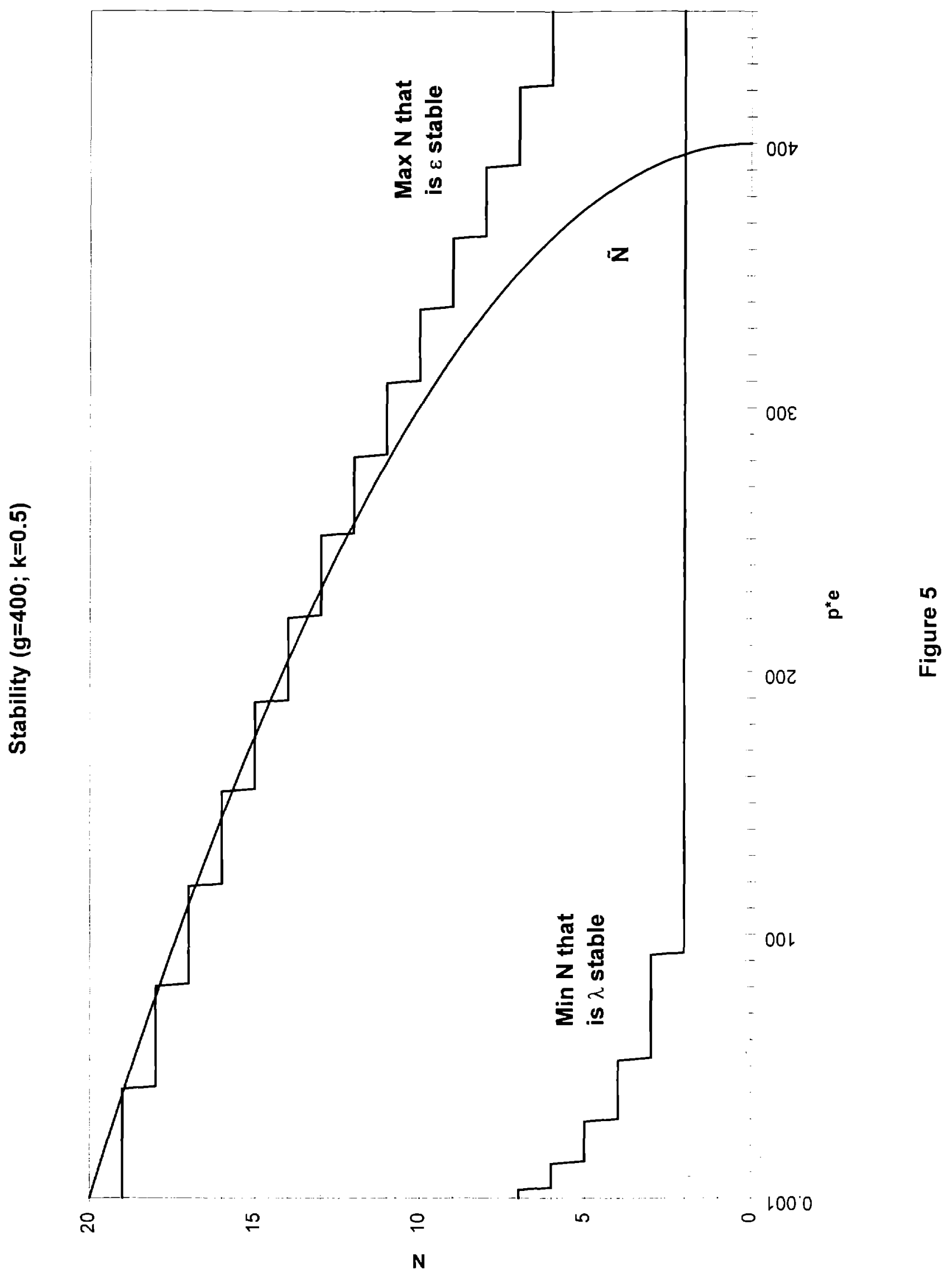




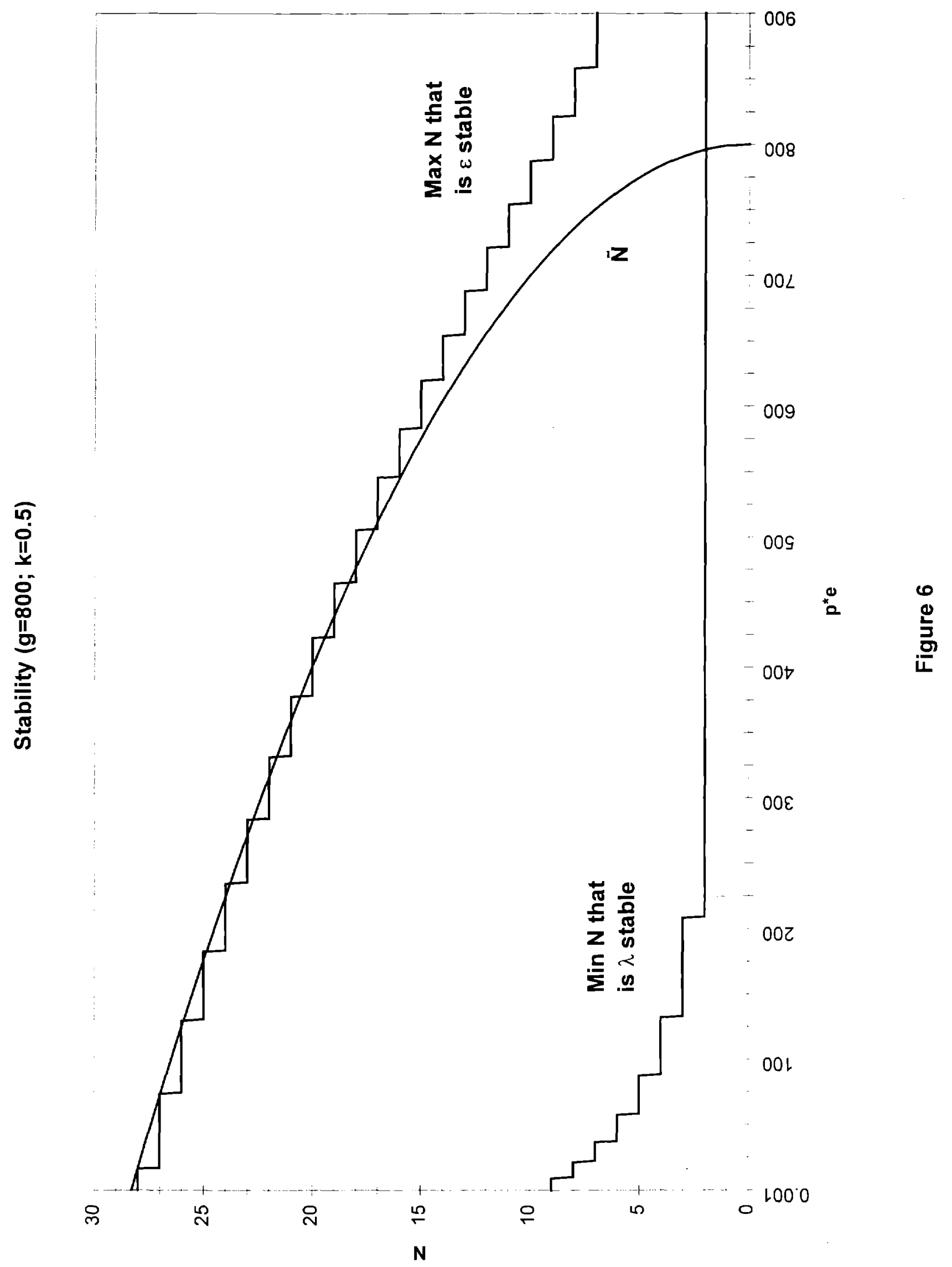




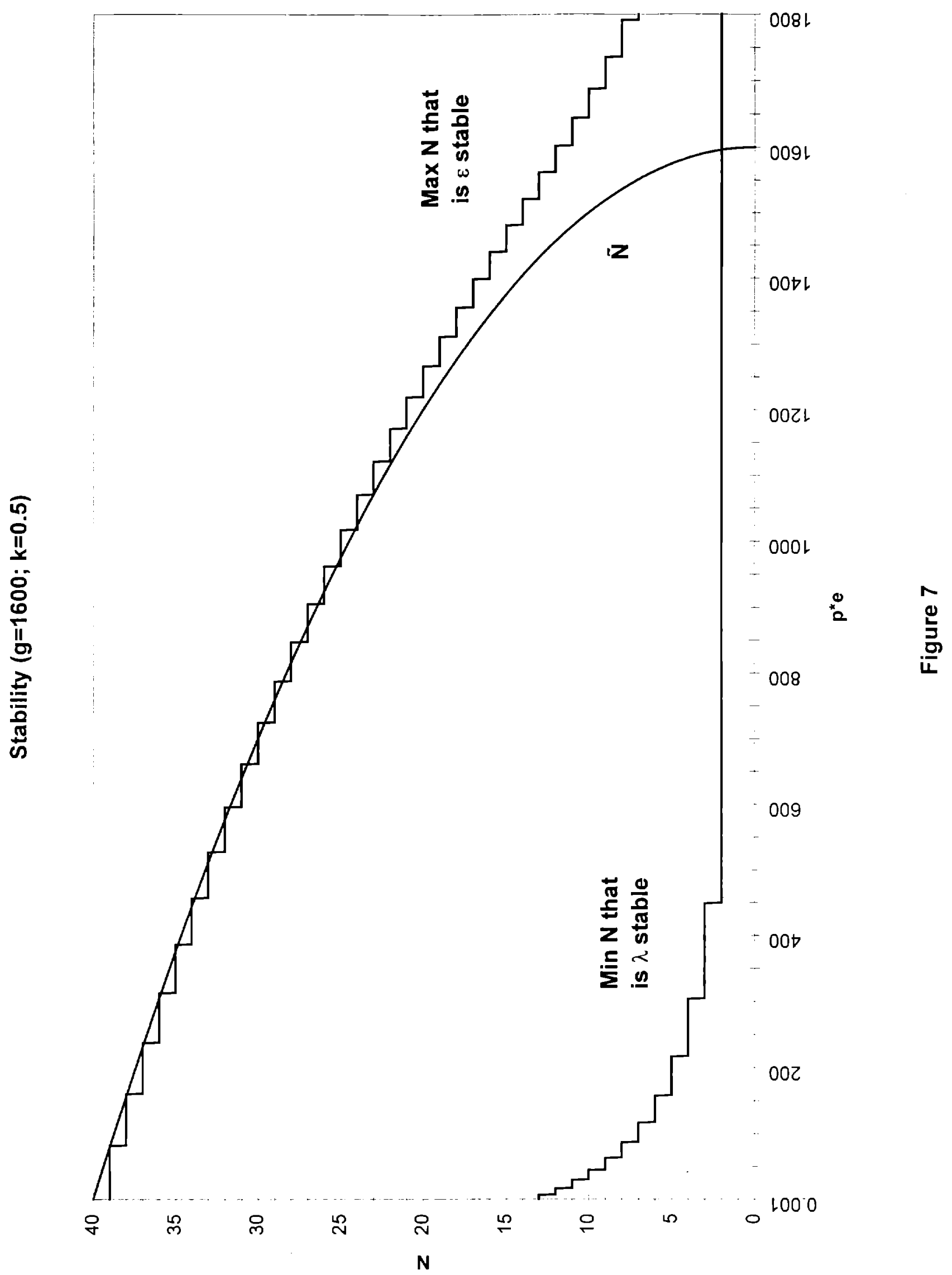

